\title{
Local Corticotropin-Releasing Factor Signaling in the Hypothalamic Paraventricular Nucleus
}

\author{
Zhiying Jiang, Shivakumar Rajamanickam, and Nicholas J. Justice \\ The Brown Foundation Institute of Molecular Medicine for the Prevention of Human Diseases, The University of Texas Health Science Center at Houston, \\ Houston, TX, 77030
}

Corticotropin-releasing factor (CRF) neurons in the hypothalamic paraventricular nucleus (PVN) initiate hypothalamic-pituitaryadrenal axis activity through the release of CRF into the portal system as part of a coordinated neuroendocrine, autonomic, and behavioral response to stress. The recent discovery of neurons expressing CRF receptor type 1 (CRFR1), the primary receptor for CRF, adjacent to CRF neurons within the PVN, suggests that CRF also signals within the hypothalamus to coordinate aspects of the stress response. Here, we characterize the electrophysiological and molecular properties of PVN-CRFR1 neurons and interrogate their monosynaptic connectivity using rabies virus-based tracing and optogenetic circuit mapping in male and female mice. We provide evidence that CRF neurons in the PVN form synapses on neighboring CRFR1 neurons and activate them by releasing CRF. CRFR1 neurons receive the majority of monosynaptic input from within the hypothalamus, mainly from the PVN itself. Locally, CRFR1 neurons make GABAergic synapses on parvocellular and magnocellular cells within the PVN. CRFR1 neurons resident in the PVN also make long-range glutamatergic synapses in autonomic nuclei such as the nucleus of the solitary tract. Selective ablation of PVN-CRFR1 neurons in male mice elevates corticosterone release during a stress response and slows the decrease in circulating corticosterone levels after the cessation of stress. Our experiments provide evidence for a novel intra-PVN neural circuit that is activated by local CRF release and coordinates autonomic and endocrine function during stress responses.

Key words: CRF; CRFR1; CRH; CRHR1; HPA axis; stress

\section{Significance Statement}

The hypothalamic paraventricular nucleus (PVN) coordinates concomitant changes in autonomic and neuroendocrine function to organize the response to stress. This manuscript maps intra-PVN circuitry that signals via CRF, delineates CRF receptor type 1 neuron synaptic targets both within the PVN and at distal targets, and establishes the role of this microcircuit in regulating hypothalamic-pituitary-adrenal axis activity.

\section{Introduction}

The stress response is a conserved mechanism vital for survival, in which the activation of the hypothalamic-pituitary-adrenal (HPA) axis serves a pivotal function. HPA axis activity is initiated by the release of corticotropin-releasing factor (CRF) from neu-

\footnotetext{
Received May 30, 2017; revised Dec. 13, 2017; accepted Dec. 19, 2017.

Author contributions: Z.J. and N.J.J. designed research; Z.J., S.R., and N.J.J. performed research; Z.J., S.R., and N.J.J. contributed unpublished reagents/analytic tools; Z.J., S.R., and N.J.J. analyzed data; Z.J., S.R., and N.J.J. wrote the paper.

This work was supported by funding from the University of Texas Health Science Center at Houston, and National Institutes of Health Grants R56-MH-114032 (N.J.) and R01-MH-112768 (N.J.). We thank Dr. Benjamin Arenkiel and Dr. Jennifer Selever at Baylor College of Medicine for providing viral preparations. We also thank Dr. Albert Hunt Jr. for helping with mouse colonies and stereotaxic injections; Dr. Qingchun Tong and Dr. Yungang Lu for use of the electrophysiology rig; and Dr. Zhengmei Mao for helping with the confocal imaging.

The authors declare no competing financial interests.

Correspondence should be addressed to Dr. Nicholas J. Justice, Institute of Molecular Medicine, University of Texas Health Sciences Center, 1825 Pressler Street, Houston, TX 77030. E-mail: Nicholas.J.Justice@uth.tmc.edu. DOI:10.1523/JNEUROSCI.1492-17.2017

Copyright $\odot 2018$ the authors $\quad 0270-6474 / 18 / 381874-17 \$ 15.00 / 0$
}

rons in the hypothalamic paraventricular nucleus (PVN), leading to the release of pituitary Adrenocorticotropic hormone (ACTH) (Vale et al., 1981). ACTH, in turn, travels through the circulation and causes the release of glucocorticoids by the adrenal glands to marshal cognitive and metabolic resources to cope with acute threats, and to prepare the organism for future stress events (Dallman and Yates, 1967; Vale et al., 1981; Swanson et al., 1983; McEwen and Sapolsky, 1995; Ulrich-Lai and Herman, 2009). HPA axis activity is exquisitely regulated, and CRF release is coordinated with multiple other endocrine and autonomic circuits to achieve a unified stress response (Leach and Taylor, 1980; Sutton et al., 1982; Gosnell et al., 1983; Brown and Fisher, 1985; Spina et al., 1996). Dysregulation of the HPA axis has been implicated in both endocrine and anxiety-related disorders including depression and post-traumatic stress disorder (Yehuda et al., 1991; Contarino et al., 1999; Chrousos, 2000; Pervanidou and Chrousos, 2010). We identified a population of neurons in the PVN that present a new control and integration locus for the regulation of 
the HPA axis and coordination of the stress response (Justice et al., 2008; Ramot et al., 2017). These neurons express the primary receptor for CRF, CRF receptor type 1 (CRFR1), allowing them to respond to locally released CRF to regulate and coordinate neuronal activation at the level of the PVN, and to modulate HPA axis output (Ramot et al., 2017). However, the electrophysiological and molecular phenotype of these neurons and how they interface with well characterized neuronal circuits that control and coordinate responses to stress, remain unclear.

The PVN contains cell bodies of diverse neuronal types, which have been classified based on their anatomic, molecular, and electrical properties (Swanson and Kuypers, 1980; Swanson et al., 1983; Liposits, 1993; Herman et al., 2003; Ulrich-Lai and Herman, 2009; Biag et al., 2012). Type I neurons are magnocellular neurons that secrete arginine vasopressin (AVP) or oxytocin (OT; Hoffman et al., 1991), express a pronounced A-type $\mathrm{K}^{+}$ current-mediated transient outward rectification and project to the posterior pituitary to release AVP or OT directly into the circulation. Type II neurons are neurosecretory parvocellular neurons that synthesize and secrete CRF or thyrotropin-releasing hormone (TRH), and project to the median eminence to control hormone release from the anterior pituitary and initiate the HPA and hypothalamic-pituitary-thyroid axes, respectively (Vale et al., 1981; Hoffman et al., 1991; Tasker and Dudek, 1991; Luther and Tasker, 2000; Lechan and Fekete, 2006). Type III neurons are termed non-neurosecretory parvocellular neurons, express a $\mathrm{Ca}^{2+}$-dependent low-threshold spike (LTS), project to the brainstem and spinal cord, and control sympathetic activity (Stern, 2001; Luther et al., 2002; Lee et al., 2008), thus they are referred to as preautonomic or presympathetic neurons.

Although each type of PVN neuron has distinct efferent projection targets, emerging evidence suggests that neurons within the PVN communicate with one another to coordinate neuroendocrine responses to stress (Neumann et al., 1996; Ferguson et al., 2008; Son et al., 2013). A CRF-mediated intra-PVN microcircuit has been revealed by the recent discovery of a novel population of neurons in the PVN that express CRFR1 (Justice et al., 2008; Ramot et al., 2017). Here, we electrophysiologically and anatomically characterize this new population of CRFR1-expressing neurons in mice. We establish their local and long-range connectivity using channelrhodopsin-2 (ChR2)-assisted circuit mapping and rabies virus-based monosynaptic tracing. Finally, we selectively ablate these neurons to determine their role in HPA axis regulation. These experiments define an intra-PVN microcircuit that signals via CRF to control HPA axis responses, mediates local cross talk between different populations of PVN neurons, and transmits PVN output to brainstem autonomic targets.

\section{Materials and Methods}

Animals. All procedures were approved by the University of Texas Health Science Center at Houston Institutional Animal Care and Use Committee, in accordance with National Institutes of Health guidelines. Mice were group-housed, bred, and raised in a facility with controlled temperature and humidity, and had ad libitum access to food and water. Experiments were conducted with Crfrl-gfp, Crfrl-cre, and Crf-cre mice. Both males and females were used except in diphtheria toxin receptor (DTR) experiments in which only males were used. The Crfrl-gfp mouse line has been previously characterized (Justice et al., 2008). The Crfrl-cre mouse was generated using a similar bacterial artificial chromosome (BAC) transgenesis strategy as the Crfr1-gfp mouse. Briefly, a BAC (rp23-239f10, Children's Hospital Oakland Research Institute, Oakland, CA) containing the entire genomic locus of CRFR1 was modified using recombineering (Liu et al., 2003; Chan et al., 2007). A cassette encoding iCre-p2A-tdTomato-PA was inserted in the first exon at the site of the ATG start codon for CRFR1.
Modified BAC DNA was purified and injected into single-celled oocytes to generate transgenic offspring (Genetically Engineered Mouse Core, Baylor College of Medicine, Houston, TX). Three independent transgenic lines were recovered, of which one (CRFR1-cre) had the best colocalization of Cre/ ${ }^{\text {td }}$ tomato with CRFR1-GFP. The Crf-cre transgenic mouse line was purchased from The Jackson Laboratory [B6(Cg)-Crhtml(cre)Zjh/J, stock \#012704] and has been previously validated (Taniguchi et al., 2011; Wamsteeker Cusulin et al., 2013a; Chen et al., 2015). Crfrl-gfp;crf-cre mice were generated by crossing Crfrl-gfp transgenic mice with Crf-cre knock-in mice. Crfr1-gfp;Crf-cre; Ai9 mice were generated by further crossing the Crfr1-gfp; Crf-cre mice with Ai9 mice. Crfr1-cre;Ai9 mice were generated by crossing Crfrl-cre transgenic mice with Ai9 mice. Mice for all experiments were maintained on a C57BL/6 background.

Stereotaxic surgeries. Under deep isoflurane anesthesia, glass capillaries were lowered into the brains of 8 - to 10 -week-old mice using a stereotaxic apparatus (Stoelting) using the following coordinates (distance from bregma): Anterior-Posterior, -0.2 to $-0.3 \mathrm{~mm}$; Medial-Lateral, \pm 0.2 $\mathrm{mm}$; Dorsal-Ventral, $-5.1 \mathrm{~mm}$. Recombinant viruses were bilaterally injected with a Nanoject II Auto-Nanoliter Injector (Drummond Scientific) in the following volumes for each injection site: AAV2-EF1a-DIOhChR2(H134R)-EYFP (UNC Vector Core, Chapel Hill, NC; $3.9 \times 10^{12}$ $\mathrm{GC} / \mathrm{ml}, 100 \mathrm{nl}$ ), helper viruses carrying TVA-mCherry and Rabies G (rAAV1-EF1a-FLEX-TVA-mCherry, $4 \times 10^{12} \mathrm{GC} / \mathrm{ml}$, and rAAV1-CAFLEX-G, $4 \times 10^{12} \mathrm{GC} / \mathrm{ml}, 1: 1$ mixture, $100 \mathrm{nl}$ ), AAV-EF1a-DIOhChR2(H134R)-p2A-Ruby (Baylor College of Medicine (BCM), Houston, TX; $150 \mathrm{nl}$ ), AAV-EF1A-FLEX-synaptophysin-eYFP (BCM, $100 \mathrm{nl}$ ), AAV-EF1a-FLEX-DTR-YFP (BCM, $\left.3.98 \times 10^{12} \mathrm{GC} / \mathrm{ml}, 300 \mathrm{nl}\right)$, AAVEF1a-DIO-eYFP (UNC Vector Core, $4.21 \times 10^{12} \mathrm{GC} / \mathrm{ml}, 100 \mathrm{nl}$ ), AAVhsyn-DIO-mCherry (UNC Vector Core, $3.9 \times 10^{12} \mathrm{GC} / \mathrm{ml}, 100 \mathrm{nl}$ ), or pseudotyped rabies virus EnvA-SAD $\Delta$ G-eGFP; (a gift from Dr. Benjamin Arenkiel, BCM, 300-500 nl). Mice were allowed to recover for at least 3 weeks before being used in experiments. For rabies viral tracing studies, mice were killed $7 \mathrm{~d}$ after the second injection. For DTRmediated cell ablation, mice (both control and DTR mice) were given a single dose of diphtheria toxin (DT; $50 \mu \mathrm{g} / \mathrm{kg}$, i.p.), at least $72 \mathrm{~h}$ before being used in experiments (Saito et al., 2001).

Acute brain slices preparation and in vitro electrophysiology recordings. Electrophysiological experiments were conducted in acutely prepared hypothalamic slices, as previously described (Nahar et al., 2015; Ramot et al., 2017). Briefly, mice (8-12 weeks old) were deeply anesthetized with Avertin (intraperitoneally) and transcardially perfused with ice-cold cutting solution containing the following (in $\mathrm{mM}$ ): 75 sucrose, $73 \mathrm{NaCl}, 26$ $\mathrm{NaHCO}_{3}, 2.5 \mathrm{KCl}, 1.25 \mathrm{NaH}_{2} \mathrm{PO}_{4}, 15$ glucose, $7 \mathrm{MgCl}_{2}$, and $0.5 \mathrm{CaCl}_{2}$, saturated with $95 \% \mathrm{O}_{2} / 5 \% \mathrm{CO}_{2}$. The brains were quickly removed from the skull and blocked, and the caudal face of the block was glued to the specimen plate of the buffer tray then immersed in ice-cold cutting solution. Coronal slices $(280 \mu \mathrm{m})$ containing either the hypothalamic PVN or nucleus of the solitary tract (NTS) were sectioned using a Leica VT $1000 \mathrm{~S}$ Vibratome and transferred to a holding chamber with artificial CSF (aCSF) containing the following (in $\mathrm{mM}$ ): $123 \mathrm{NaCl}, 26 \mathrm{NaHCO}_{3}$, $2.5 \mathrm{KCl}, 1.25 \mathrm{NaH}_{2} \mathrm{PO}_{4}, 10$ glucose, $1.3 \mathrm{MgCl}_{2}$, and $2.5 \mathrm{CaCl}_{2}$, and saturated with $95 \% \mathrm{O}_{2} / 5 \% \mathrm{CO}_{2}$ at $31-33^{\circ} \mathrm{C}$ for $30 \mathrm{~min}$, then maintained at room temperature for at least $1 \mathrm{~h}$ to allow for recovery before any electrophysiological recordings.

Individual slices were transferred from the holding chamber to a recording chamber in which they were submerged and continuously perfused with aCSF. Whole-cell patch-clamp recordings were performed in the PVN or NTS under infrared-differential interference contrast visualization at $\sim 32^{\circ} \mathrm{C}$ on a fixed-stage, upright microscope (model BX51WI, Olympus) equipped with a water-immersion $40 \times$ objective. Pipettes with a resistance of 3-5 $\mathrm{M} \Omega$ were pulled from borosilicate glass (outer diameter, $1.5 \mathrm{~mm}$; inner diameter, $1.1 \mathrm{~mm}$; Sutter Instruments) using a horizontal puller (P-97, Sutter) and filled with an internal patch solution containing the following (in mM): $142 \mathrm{~K}$-gluconate, 10 HEPES, 1 EGTA, $2.5 \mathrm{MgCl}_{2}, 4 \mathrm{Mg}$-ATP, $0.3 \mathrm{Na}$-GTP, and $10 \mathrm{Na}_{2}$-phosphocreatine, adjusted to $\mathrm{pH} 7.25-7.35$, osmolality $295-305$ with $\mathrm{KOH}$. The liquid junction potential was not corrected, and series resistance (Rs) was bridge balanced. For all recordings, series resistance (Rs) $>25 \mathrm{M} \Omega$ were not 
included in analysis. For experiments in the hypothalamus, neurons were excluded from analysis if their input resistance was $<500 \mathrm{M} \Omega$.

To excite channelrhodopsin in brain slices in optogenetic experiments, an optical fiber was placed close to the recording site (15$30 \mu \mathrm{m}$ above the slice, $100-200 \mu \mathrm{m}$ away from the tip of the recording electrode) to deliver light from a laser source ( $473 \mathrm{~nm}$ PSU-III-LED laser system, Opto Engine). Laser light was delivered in pulses, with a pulse duration of $0.5-5 \mathrm{~ms}$ and an intensity $3.5-6 \mathrm{~mW}$. For laser-induced spiking of ChR2-expressing neurons and laser-evoked EPSCs/IPSCs, light pulses were adjusted to the minimum power required to evoke a reliable single-peak response from trial to trial; for laser activation of CRF neurons while recording CRFR 1 neurons, $5 \mathrm{~ms}$ light pulses were used for all experiments, because the response is not time locked to a laser, and $5 \mathrm{~ms}$ is sufficient to evoke a reliable single action potential in most ChR2expressing neurons that we tested. Laser frequencies for each experiment were specified in the results.

Single-cell reverse transcription PCR. Single-cell reverse transcription PCR was performed as previously described (Gómez-Lira et al., 2005; Lazarenko et al., 2009; Pfeffer et al., 2013; Ramot et al., 2017).

Reagents. The following drugs were kept at $-20^{\circ} \mathrm{C}$ as stock solutions and were dissolved in aCSF to their final concentration on the day of the experiments: CRF peptides (30 nm; courtesy of Dr. J. Rivier, The Salk Institute, La Jolla, CA), DL-AP5 sodium salt (AP5; $50 \mu \mathrm{M}$; Tocris Bioscience), DNQX disodium salt (DNQX; 10-20 $\mu \mathrm{m}$; Tocris Bioscience), picrotoxin (50 $\mu \mathrm{M}$; Tocris Bioscience), Antalarmin hydrochloride (300 nM; Tocris Bioscience), bicuculline (Bic; $10-40 \mu \mathrm{M}$; Sigma-Aldrich), tetrodotoxin (TTX; $0.5-1 \mu \mathrm{M}$; Tocris Bioscience). When DMSO was used as solvent, the final concentration of DMSO in the perfusate was $\leq 0.1 \%$.

Immunofluorescence and imaging. For histology studies, adult mice (8-12 weeks old) were deeply anesthetized with Avertin then transcardially perfused with $\mathrm{PBS}$ followed by $4 \%$ paraformaldehyde (PFA) in PBS. Brains were removed, fixed in $4 \%$ PFA at $4^{\circ} \mathrm{C}$ overnight, then equilibrated in $30 \%$ sucrose, sectioned ( $30 \mu \mathrm{M}$, coronal sections) into four series of sections on a frozen sliding microtome (SM 2000R, Leica), and stored in cryoprotectant solution at $-20^{\circ} \mathrm{C}$. Brain sections were rinsed with PBS and incubated with primary antibodies [goat anti-GFP, 1:1000, catalog \#600-101-21, Rockland (RRID:AB_218182); rabbit anti-CRF, 1:1000, rc70, courtesy of Dr. Wylie Vale, The Salk Institute, La Jolla, CA; goat anti-CRFR1, 1:100, catalog \#EB07553, Everest Biotech (RRID: AB_2229860); rabbit anti-GFP, 1:1000, catalog \#A6455, Invitrogen (RRID: AB_221570); rabbit anti-vasopressin, 1:1000, catalog \#H-065-07, Phoenix Pharmaceuticals; mouse anti-oxytocin, 1:500, catalog \#MAB5296, Millipore (RRID:AB_2157626); mouse anti-chromogranin A (CGA), catalog \#NBP229428, Novus Biologicals] with $2 \%$ normal donkey serum and $0.4 \%$ Triton X-100 at $4^{\circ} \mathrm{C}$ overnight. They were then incubated in respective secondary antibodies (all secondaries were obtained from Jackson ImmunoResearch: Alexa Fluor 488 donkey anti-goat, catalog \#705-546-147 (RRID: AB_2340430); Alexa Fluor 488 donkey anti-rabbit, catalog \#711-546-152 (RRID:AB_2340619); Alexa Fluor 594 donkey anti-goat, catalog \#705-586147 (RRID:AB_2340434); Alexa Fluor 647 donkey anti-rabbit, catalog \#711606-152 (RRID:AB_2340625); Alexa Fluor 647 donkey anti-mouse, catalog \#715-606-150 (RRID:AB_2340865); 1:1000] at room temperature for $1 \mathrm{~h}$. Sections were washed in PBS then mounted and imaged on a confocal microscope (model TCS SP5, Leica ). For identification of CRF soma in pseudotyped rabies virus (PTRV) experiments, mice were treated with colchicine (10 $\mu \mathrm{g} ; 8 \mathrm{mg} / \mathrm{ml}$, i.c.v.) $48 \mathrm{~h}$ before being killed.

Image acquisition and processing. Images were captured using a confocal microscope (model TCS SP5, Leica) and processed with Fiji ImageJ. For immunofluorescence studies, $z$-stacks of ROIs (with six to eight optical sections; $1 \mu \mathrm{m} /$ section; pinhole $=1$ airy unit; line average $=3$; pixels, $1024 \times 1024$ ) were captured at $10 \times, 20 \times, 40 \times$, and $63 \times$ using neuroanatomical landmarks found in a mouse brain atlas (Paxinos and Franklin, 2008). Images presented in this article were produced by maximal projection of the $z$-stacks, with brightness and contrast adjusted in ImageJ.

Colocalization analysis was performed on selected brain regions in at least three mouse brains for each experiment (as shown by sample size $n$ ). One single focal plane $(1 \mu \mathrm{m})$ from each $40 \times$ magnification image stack containing the ROI (two to three sections/mouse) was quantified using CellProfiler 2.2.0.

Immobilization stress and corticosterone measurements. For immobilization stress, mice were fixed to flat cutting boards with adhesive tape in the prone position for $2 \mathrm{~h}$. Blood samples were collected by submandibular bleed under basal conditions and at different time points during immobilization stress exposure. Serum samples were stored at $-20^{\circ} \mathrm{C}$ until assayed using a MILLIPLEX MAP Rat Stress Hormone Magnetic Bead Panel-Endocrine Multiplex Assay (EMD Millipore) following the manufacturer manual.

Experimental design and statistical analysis. Data are presented as the mean \pm SEM. Electrophysiological data were analyzed with Clampfit 10.7 (Molecular Devices), and all statistical analyses were performed with SigmaPlot 11.0 (Systat Software), and details are indicated in the results of each section. Difference were considered as significant at $p<0.05$ $\left({ }^{*} p<0.05,{ }^{* *} p<0.01\right)$. Input resistance was calculated from short -10 $\mathrm{mV}$ hyperpolarization steps at approximately $-60 \mathrm{mV}$. Resting membrane potential was measured in zero current $(I=0)$ mode for at least 3 min. Threshold was defined as the mean potential of the trace in which a spike was first induced. Parameters of the spike (amplitude, half-width, and afterhyperpolarization) were calculated using the first spike above threshold. Spike amplitude is defined as peak-to-peak amplitude (depolarization peak minus afterhyperpolarization peak). Afterhyperpolarization is defined as the afterhyperpolarization peak minus the mean potential of the trace. Spike frequency adaptation (SFA) was defined as (last ISI)/(first ISI) (Inter-spike interval, ISI). Measurements were taken in the last trace before depolarization block or the trace with $+25 \mathrm{pA}$ depolarization current for $3 \mathrm{~s}$ (SFA ratio $=1.0$ represents no adaptation, while a larger SFA ratio represents higher adaptation). Sag ratio was defined as the [voltage difference at the steady state of a hyperpolarization current (Fig. 1, $\Delta 2$ )/(voltage difference at the beginning of a hyperpolarization current (Fig. $2 A, \Delta 1$ )] smaller Sag ratio represents more hyperpolarization-activated currents.

For pharmacological and optogenetic studies, baselines were calculated from firing rates (average number of spikes/s, in hertz) before drug application or laser exposure (3-10 $\mathrm{min}$ ). Bath-applied drug effects were calculated from the last 3 min during drug application. Optical effects were calculated from the average firing rate during laser exposure (2$5 \mathrm{~min})$. A two-tailed paired Student's $t$ test was used to compare the baseline and treatment within the group, and ANOVA and post hoc tests were used to compare the effects between groups. Sample size $n$ represents the number of neurons recorded. All experiments include both male and female mice, with the exception of corticosterone measurement, in which only male mice were used. A minimum of three mice were used for each experimental group. For Figures 5 and 9, sample size $n$ represents the number of animals used.

\section{Results}

\section{PVN-CRFR1 neurons respond to CRF in the PVN}

A BAC transgenic mouse, which expresses GFP under the control of the entire promoter/enhancer complement of CRFR1, expresses GFP in a population of neurons in the PVN (Justice et al., 2008; Ramot et al., 2017). These neurons do not express any classical markers of PVN neurons, including corticotropin releasing factor (CRF), TRH, AVP, and OT (Ramot et al., 2017). To verify that the expression of GFP is indeed in cells that express CRFR1 protein, we stained sections of CRFR1-GFP brain sections containing the PVN with antibodies for CRFR1. Immunofluorescent signal is visible in cells that express the CRFR1-GFP transgene (Fig. 1A-C). CRFR1-GFP neurons intercalate with CRF neurons in the PVN. In animals carrying the CRFR1-GFP transgene and CRF-Cre with a tomato reporter (Ai9), we can see $\mathrm{GFP}^{+}$neurons both within and surrounding the tight cluster of CRF neurons in the PVN (Ramot et al., 2017). At high magnification, we observe many interaction points between these two neuronal populations. After staining for CRF peptide and CGA, a large dense core vesicle (LDCV) marker, we see colocalization of 

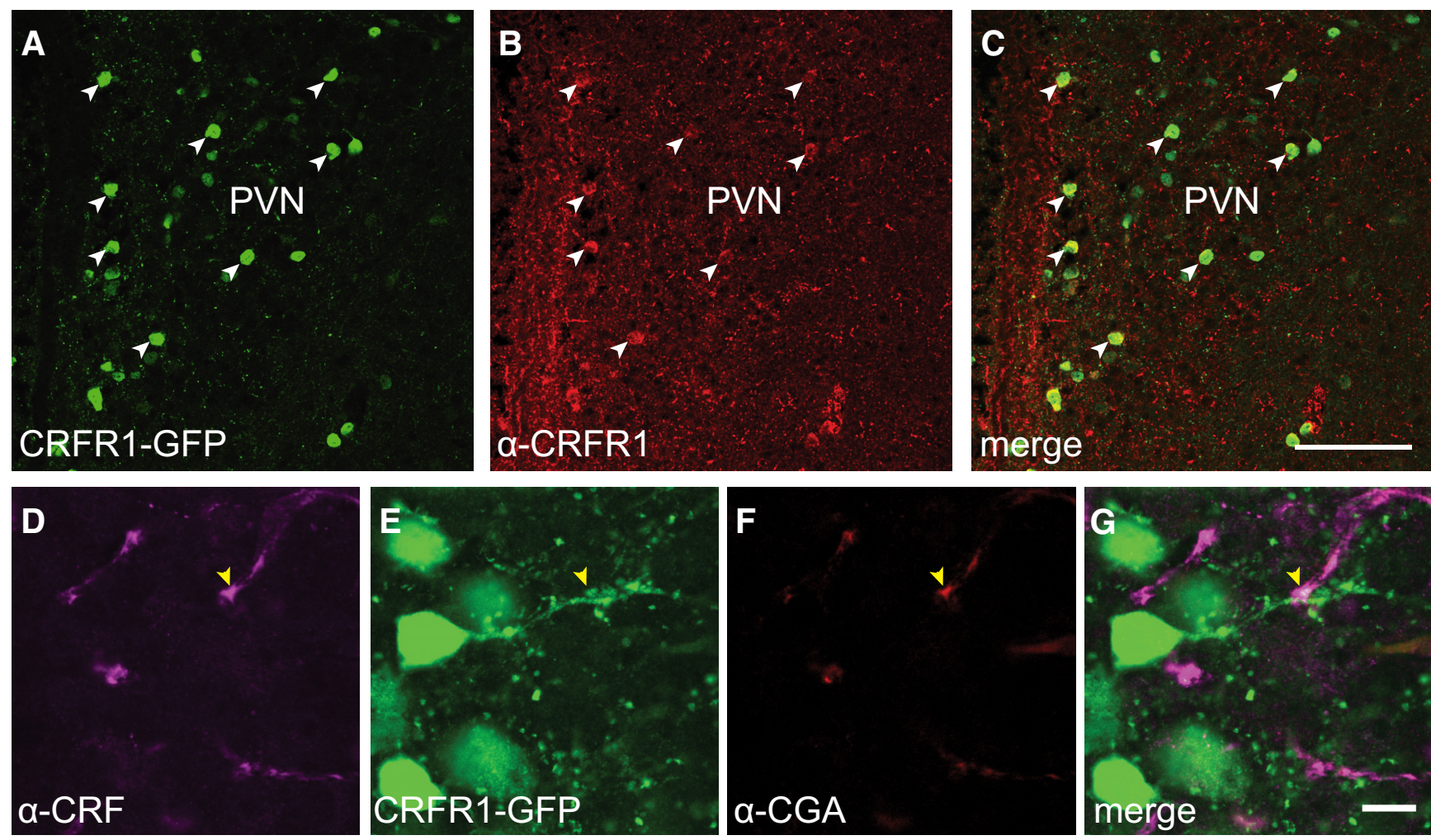

H

Baseline

$+\operatorname{CRF}(30 \mathrm{nM})$
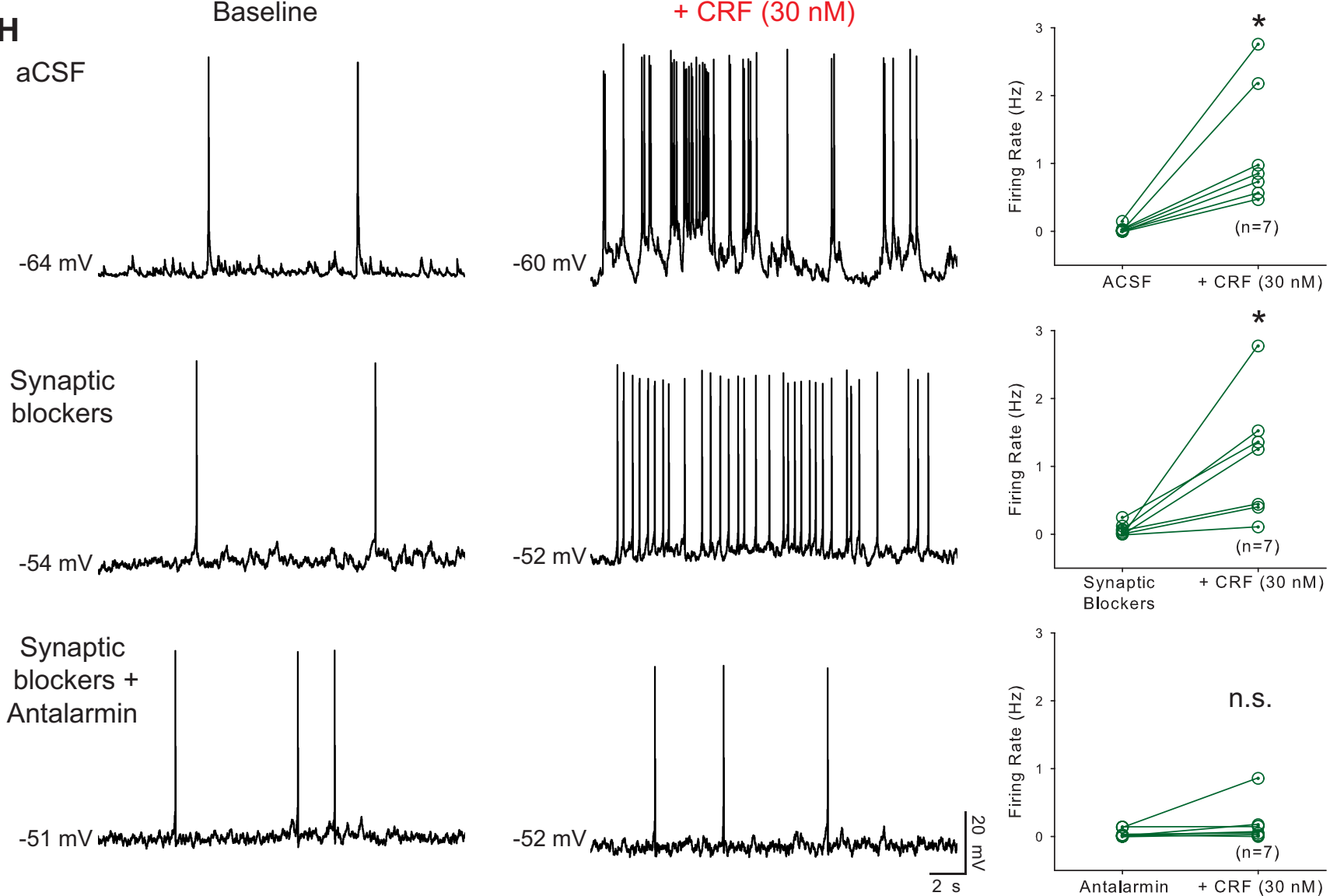

Figure 1. CRFR1-GFP neurons in the PVN receive contacts from CRF neurons and are activated by CRF. $A-C$, Validation of CRFR1-GFP transgenic mice. $A, B$, Expression of the CRFR1-GFP transgene $(\boldsymbol{A})$ is highly correlated with CRFR1 receptor immunoreactivity $(\boldsymbol{B})$. C, The merged image shows colocalization (white arrowheads). Scale bar, $100 \mu \mathrm{m}$. $\boldsymbol{D}-\boldsymbol{F}$, CRF-positive fibers (D) are closely apposed to CRFR1-GFP neurons $(\boldsymbol{E})$, which express the LDCV marker CGA $(\boldsymbol{F})$. $\mathbf{G}$, Merged image shows a $\mathrm{CRF}^{+} / \mathrm{CGA}^{+}$puncta apposed to a CRFR1-GFP fiber (yellow arrow). Scale bar, $10 \mu \mathrm{mm}$. $\boldsymbol{H}$, CRFR1-GFP neurons express functional CRFR1 receptors. Left, Representative traces of CRFR1-GFP neurons before and during CRF application in aCSF (top traces), in fast synaptic blockers (AP5, DNQX, and picrotoxin; middle traces), and in synaptic blockers plus the selective (RFR1 antagonist Antalarmin (bottom traces). Right, Summary histograms of exogenous (RF-induced changes in firing rate in aCSF (top), synaptic blockers (middle), and CRFR1 antagonist (bottom). ${ }^{*} p<0.05$. 


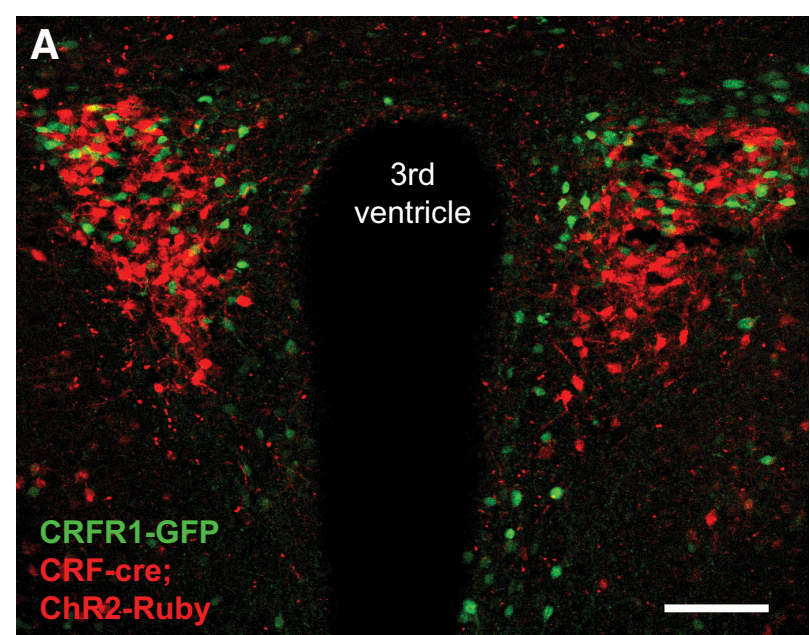

B

CRF-cre;

mCherry

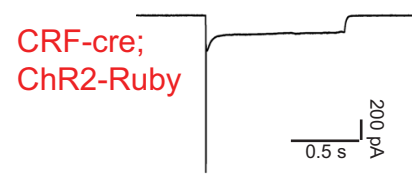

$\mathbf{F}$

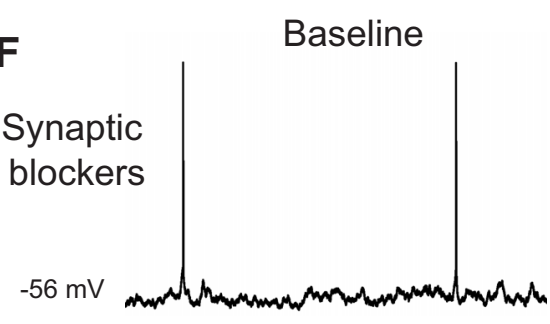

blockers

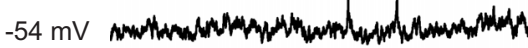
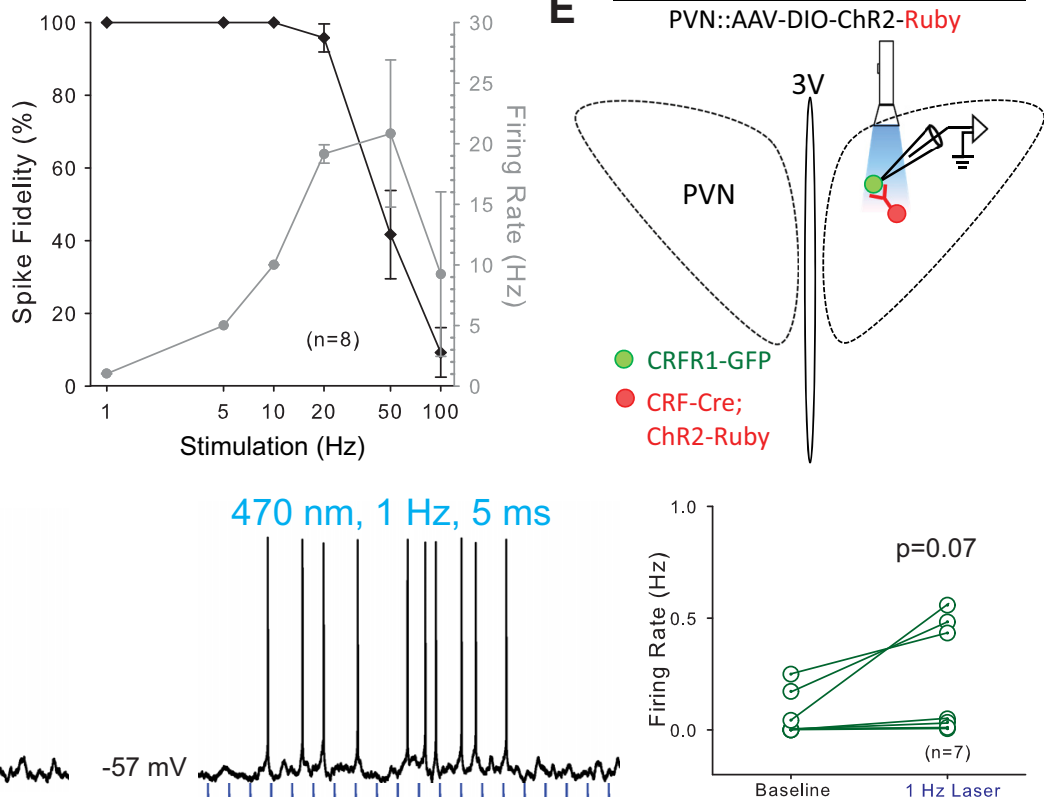

470 nm, $20 \mathrm{~Hz}, 5$ ms
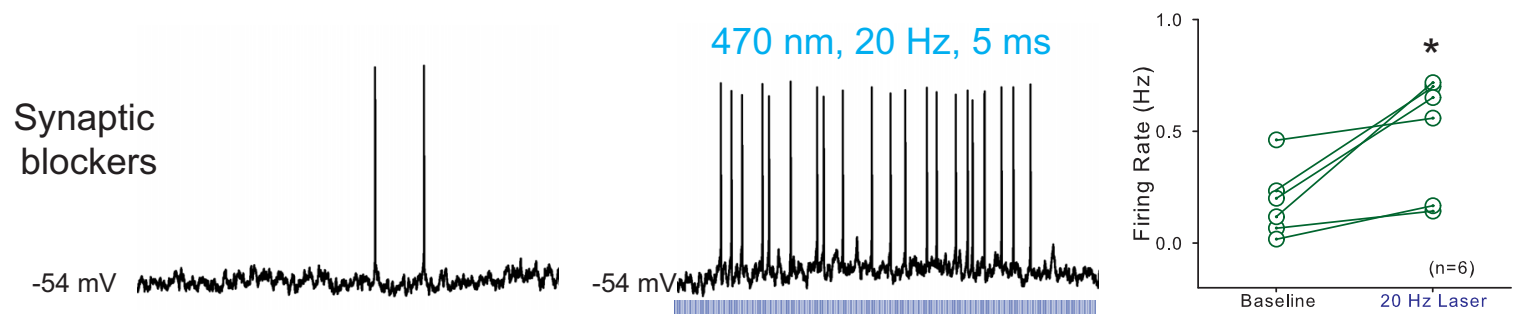

470 nm, $20 \mathrm{~Hz}, 5$ ms

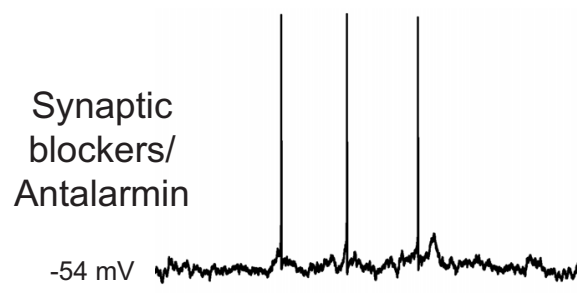

E

CRFR1-GFP;CRF-Cre

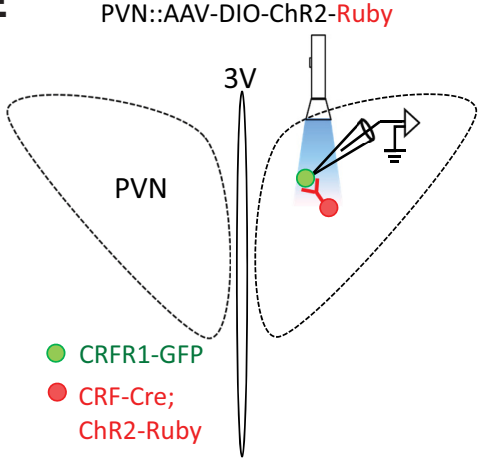

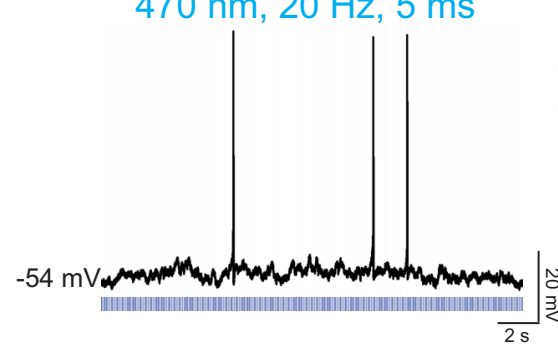

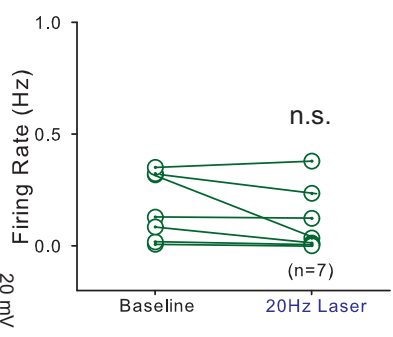

Figure 2. PVN-CRFR1-GFP neurons are activated by locally released CRF. A, Example micrograph of the PVN from an animal with the genotype CRFR1-GFP; CRF-Cre, injected in the PVN with AAV encoding (re-dependent ChR2 with a 2A-Ruby reporter. CRFR1 neurons (green) are intercalated with CRF-cre neurons that have been infected with $m$ ChR2-2A-mRuby-expressing virus (Red). Scale bar, $100 \mu \mathrm{m}$. B, Representative traces of photocurrents recorded in (RF neurons. In CRF neurons infected with ChR2-Ruby virus, photostimulation (1 s pulse) (Figure legend continues.) 
CRF-positive, CGA-positive puncta overlying interaction sites with CRFR1-GFP neurons (Fig. $1 D-G$, arrows), suggesting that CRF neurons release CRF onto CRFR1-GFP neurons in the PVN.

Next, we examined whether CRFR1 neurons are functionally responsive to CRF peptide. Although we see expression of GFP that coincides with CRFR1 immunoreactivity (Fig. $1 A-C$ ), the presence of GFP does not formally prove that CRFR1 is functional or localized appropriately to respond to release of CRF within the PVN. To determine whether CRFR1 is functional in PVN neurons expressing CRFR1-GFP, we recorded from GFP ${ }^{+}$ neurons in the PVN and bath applied CRF. Action potential thresholds were determined as described in the Materials and Methods; neurons were held at a membrane potential $\sim 5 \mathrm{mV}$ below the firing threshold. In acutely prepared hypothalamic slices from CRFR1-GFP animals, bath application of CRF (30 nM) significantly increased the firing rate of CRFR1-GFP neurons (Fig. $1 \mathrm{H}$, top panels, from $0.03 \pm 0.02 \mathrm{~Hz}$ to $1.22 \pm 0.34 \mathrm{~Hz}, n=$ $7, Z=2.366, p=0.016$, Wilcoxon signed rank test). Next, we preincubated hypothalamic slices in DNQX (10-15 $\mu \mathrm{M}$; AMPA receptor and kainate receptor antagonist), AP-5 (50 $\mu \mathrm{M}$; NMDA receptor antagonist $)$, and $\mathrm{Bic}\left(10 \mu \mathrm{M} ; \mathrm{GABA}_{\mathrm{A}}\right.$ receptor antagonist $)$ or picrotoxin (50 $\mu \mathrm{M}$; $\mathrm{GABA}_{\mathrm{A}}$ receptor antagonist) to block fast synaptic transmission. In synaptic blockers, exogenous CRF administration increased the firing rate of CRFR1-GFP neurons (Fig. $1 \mathrm{H}$, middle panels, from $0.08 \pm 0.03 \mathrm{~Hz}$ to $1.12 \pm 0.34 \mathrm{~Hz}, t_{(6)}=$ $-3.042, p=0.023$, paired $t$-test), indicating that CRF acts directly on $\mathrm{GFP}^{+}$neurons. To determine whether this is due to activation of CRFR1, we preincubated slices with the selective CRFR1 antagonist Antalarmin (300 nM). In Antalarmin, CRF no longer increased action potential firing in CRFR1-GFP PVN neurons (Fig. $1 H$, bottom panels; from $0.05 \pm 0.02 \mathrm{~Hz}$ to $0.18 \pm 0.12$ $\mathrm{Hz}, n=7, \mathrm{Z}=1.859, p=0.078$, Wilcoxon signed rank test; change in firing rate: $1.05 \pm 0.34 \mathrm{~Hz}$ in fast synaptic blockers vs $0.13 \pm 0.10 \mathrm{~Hz}$ with antalarmin preincubation; $p=0.007$, one way ANOVA on ranks). Together, these data demonstrate that CRFR1-GFP neurons in the PVN express functional CRFR1 and that it is localized appropriately to respond to bath application of CRF. Moreover, CRF is excitatory and increases action potential firing rate in CRFR1-GFP PVN neurons. We also observed that exogenous CRF decreased spontaneous excitatory postsynaptic currents (sEPSC) amplitude (82.26 $\pm 4.6 \%$ of baseline; $t_{(4)}=$ $3.86, p=0.02$, paired $t$ test) without significantly changing the frequency of events $\left(89.44 \pm 17.33 \%\right.$ of baseline; $t_{(4)}=0.61, p=$ 0.58 , paired $t$ test). Exogenous CRF failed to change the spontaneous excitatory postsynaptic currents (sEPSC) amplitude or fre-

\section{$\leftarrow$}

(Figure legend continued.) induced typical ChR2-mediated currents (bottom trace), whereas photostimulation with the same intensity and duration failed to induce photocurrent in CRF neurons infected with control virus (middle trace). C, Sample traces of action potential firing in a CRF-ChR2 neuron with 5 and $50 \mathrm{~Hz}$ optical stimulation (laser duration, 1-5 ms), firing slows with $50 \mathrm{~Hz}$ stimulation. D, Entrainment of CRF-ChR2 neurons to direct optical stimulation: percentage change in spike fidelity and ChR2-mediated CRF neurons firing $(n=8)$. $\boldsymbol{E}$, Schematic experimental setup for optogenetic activation of CRF release in the PVN. CRFR1-GFP; CRF-cre animals were injected in the PVN with AAVs encoding Cre-dependent ChR2 with a 2A-Ruby reporter. Recordings were performed on green fluorescent neurons (CRFR1-GFP) while activating CRF neurons with laser light. $\boldsymbol{F}$, Activation of CRF neurons by optical stimulation causes an increase in action potential firing in a neighboring (RFR1-GFP neuron in the presence of synaptic blockers (top traces, $1 \mathrm{~Hz}$; middle traces, $20 \mathrm{~Hz}$ ). Note that action potentials are not correlated with laser pulses. The excitatory effect is blocked by Antalarmin preincubation, indicating that the increase in firing is mediated by CRFR1 receptors (bottom traces). Right panels, Quantification of the change in firing rate of CRFR1-GFP neurons with optical activation of CRF neurons in synaptic blockers and with Antalarmin preincubation. ${ }^{*} p<0.05$. quency $(n=3)$. These findings suggest that in addition to direct excitation, CRF also decreases inhibitory synaptic strength to increase CRFR1 neuronal excitability.

\section{CRFR1 neurons are activated by local CRF release}

To functionally characterize synapses between CRF and CRFR1 neurons, we expressed channelrhodopsin in CRF neurons in the PVN by stereotaxically injecting the PVN of crfrl-gfp; crf-cre mice with Cre-dependent ChR2-RFP virus (AAV-EF1a-DIO-hChR2 (H134R)-p2A-Ruby; Fig. 2A). Using an optical fiber to deliver a $473 \mathrm{~nm}$ blue laser to the slice, we elicited large photocurrents (peak, $1313.15 \pm 94.09$ pA; steady state, $248.49 \pm 37.24 \mathrm{pA} ; n=$ 7 ; Fig. $2 B$, bottom trace), while there were no photocurrents evoked in controls (crf-cre mice injected with AAV-syn-DIOmCherry; $n=14$; Fig. $2 B$, middle). In addition, $473 \mathrm{~nm}$ laser pulse trains (1-5 ms) reliably evoked action potential firing in ChR2-RFP-positive CRF neurons up to $20 \mathrm{~Hz}$ with $96 \%$ fidelity, which could last for over 10 minutes (Fig. 2C,D). PVN CRF neurons are glutamatergic and release glutamate in the lateral hypothalamus (Füzesi et al., 2016). However, we observed laserevoked EPSCs in only 2\% (1 of 43) of recorded CRFR1-GFP neurons. Nevertheless, in the presence of synaptic blockers DNQX $(15 \mu \mathrm{M}), \mathrm{AP}-5(50 \mu \mathrm{M})$, and Bic $(10 \mu \mathrm{M})$ or picrotoxin $(50$ $\mu \mathrm{M})$, laser stimulation for $1-3 \mathrm{~min}$ led to an increase in action potential firing in 7 of 12 neurons with $1 \mathrm{~Hz}$ ( 5 ms pulses) optical stimulation (Fig. $2 F$, top panels; $0.07 \pm 0.04 \mathrm{~Hz}$ at baseline vs $0.23 \pm 0.10 \mathrm{~Hz}$ during laser exposure; $t_{(6)}=-2.17, p=0.07$, paired $t$ test), and in 6 of 9 neurons with $20 \mathrm{~Hz}$ ( $5 \mathrm{~ms}$ pulse) optical stimulation (Fig. $2 F$, middle panels; $0.18 \pm 0.06 \mathrm{~Hz}$ at baseline vs $0.49 \pm 0.11 \mathrm{~Hz}$ during laser exposure; $t_{(5)}=-3.33$, $p=0.02$, paired $t$ test). Excitation of CRFR1 neurons by optogenetic stimulation of CRF neurons was blocked by Antalarmin, a selective CRFR1 antagonist (Fig. $2 F$, bottom panels; from $0.18 \pm$ $0.06 \mathrm{~Hz}$ at baseline to $0.11 \pm 0.05 \mathrm{~Hz}$ during laser exposure; $n=$ $7, Z=-1.52, p=0.16$, Wilcoxon signed rank test). These data indicate that CRFR1 neurons in the PVN are excited by CRF released from adjacent CRF neurons.

\section{Electrical properties of CRFR1 neurons in the hypothalamic paraventricular nucleus}

Next, we investigated the electrophysiological properties of CRFR $1^{+}$neurons in the PVN. Different classes of PVN neurons have been characterized previously using electrophysiological methods combined with immunohistochemical and anatomical labeling (Luther and Tasker, 2000; Stern, 2001; Luther et al., 2002). To determine which classes PVN CRFR1 neurons belong to, we obtained whole-cell patch-clamp recordings from PVNCRFR1 neurons, identified by the expression of GFP. CRFR1$\mathrm{GFP}^{+}$neurons in the PVN display many of the passive electrophysiological characteristics described for PVN neurons previously, such as a high-input resistance $(1.09 \pm 0.09 \mathrm{G} \Omega, n=$ $22)$, and a resting membrane potential between -55 and $-70 \mathrm{mV}$ (average, $-65.12 \pm 0.73 \mathrm{mV} ; n=77$; Tasker and Dudek, 1991; Stern, 2001). In addition, CRFR1-GFP neurons display an average spiking threshold of $-53.70 \pm 0.96 \mathrm{mV}$, with an average spike amplitude of $70.91 \pm 1.47 \mathrm{mV}$ and a half-width of $1.79 \pm 0.10$ $\mathrm{ms}$, with an afterhyperpolarization of $-2.22 \pm 0.46 \mathrm{mV}(n=24)$.

We observe three subtypes of $\mathrm{GFP}^{+}$neurons in the PVN, according to their response to a $-100 \mathrm{pA}$ hyperpolarization current (Fig. $3 A$ ). The majority of neurons ( 44 of 55; 80\%) fired at least one action potential in response to a hyperpolarization current (LTS; Fig. $3 A, B$, type A), resembling the electrophysiological properties of non-neurosecretory preautonomic neurons in rats 


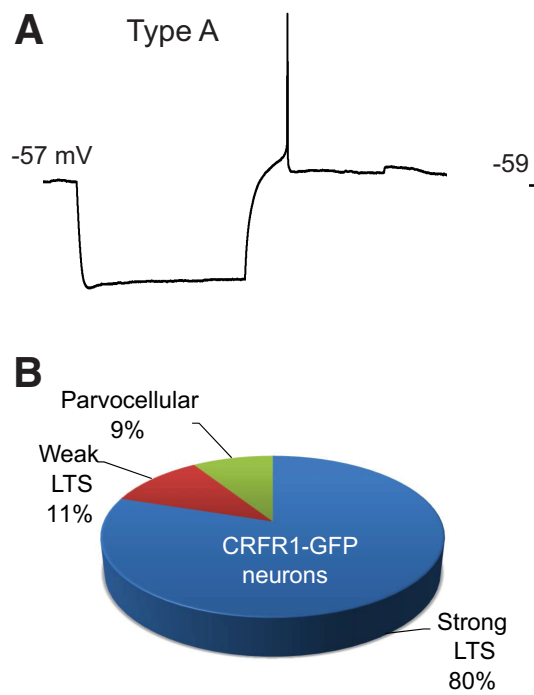

Type B

Type C
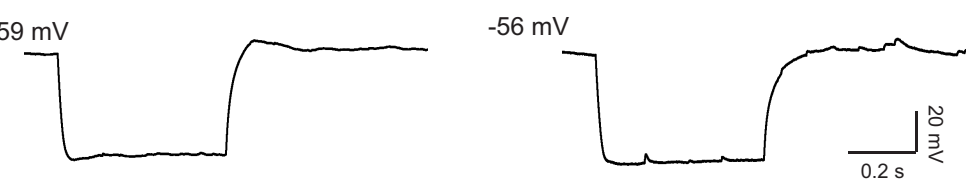

C
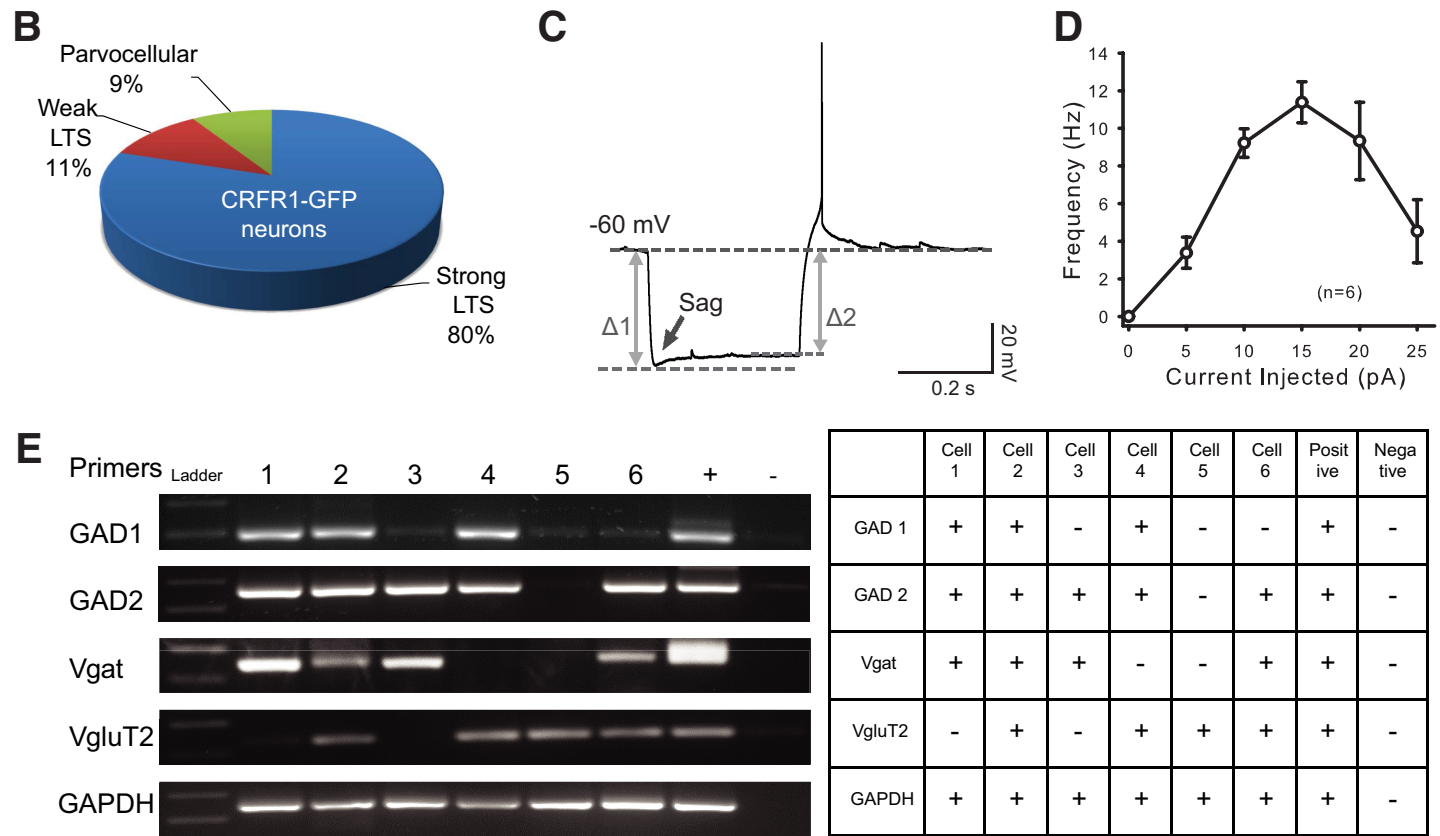

\begin{tabular}{|c|c|c|c|c|c|c|c|c|}
\hline & $\begin{array}{c}\text { Cell } \\
1\end{array}$ & $\begin{array}{c}\text { Cell } \\
2\end{array}$ & $\begin{array}{c}\text { Cell } \\
3\end{array}$ & $\begin{array}{c}\text { Cell } \\
4\end{array}$ & $\begin{array}{c}\text { Cell } \\
5\end{array}$ & $\begin{array}{c}\text { Cell } \\
6\end{array}$ & $\begin{array}{c}\text { Posit } \\
\text { ive }\end{array}$ & $\begin{array}{c}\text { Nega } \\
\text { tive }\end{array}$ \\
\hline GAD 1 & + & + & - & + & - & - & + & - \\
\hline GAD 2 & + & + & + & + & - & + & + & - \\
\hline Vgat & + & + & + & - & - & + & + & - \\
\hline VgluT2 & - & + & - & + & + & + & + & - \\
\hline GAPDH & + & + & + & + & + & + & + & - \\
\hline
\end{tabular}

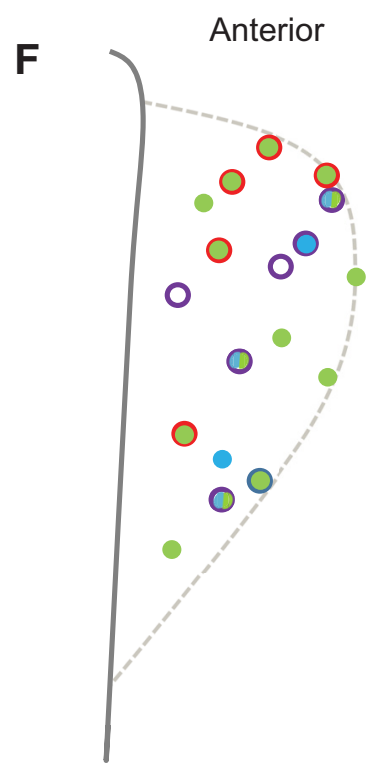

Medial
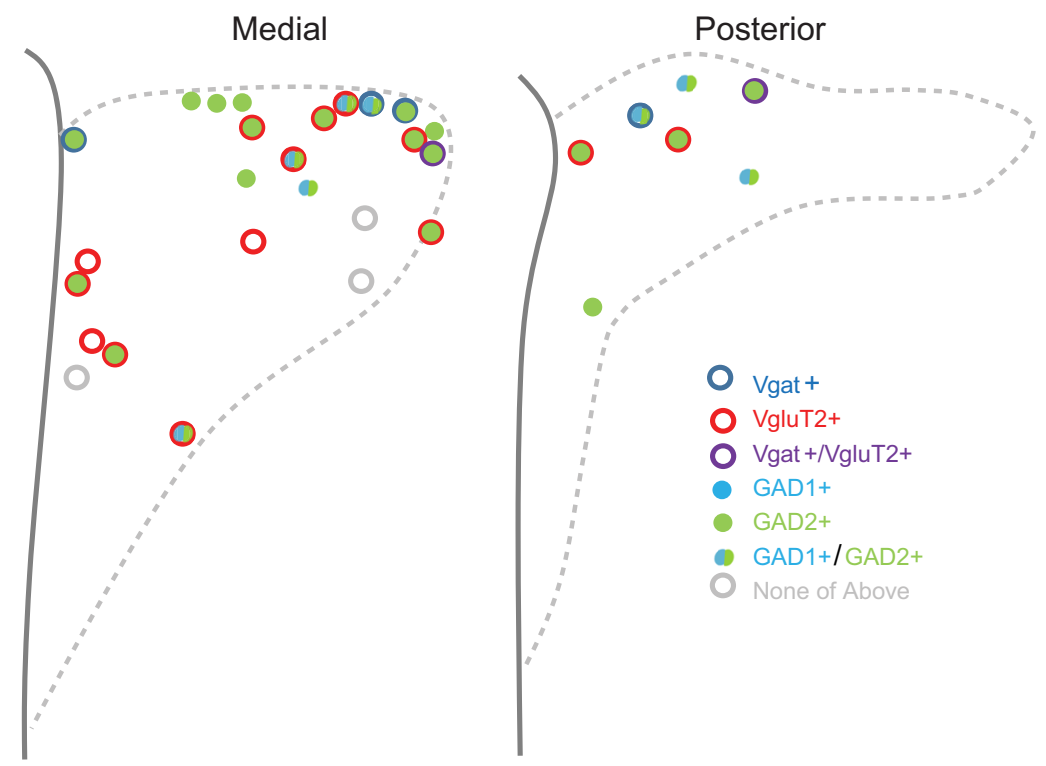

Figure 3. Electrophysiological and molecular properties of CRFR1-GFP neurons in the PVN. $A$, Representative responses of CRFR1-GFP neurons to a negative current injection step ( $-100 \mathrm{pA}, 500$ ms). $\boldsymbol{B}$, Eighty percent of the CRFR1-GFP neurons fire at least one action potential in response to a - 100 pA hyperpolarization current (type A), $11 \%$ express a small "hump" (type B), and 9\% show no LTS (type C). C, Majority CRFR1-GFP neurons express a small sag in response to a hyperpolarization current. The arrow points out the "sag," indicative of the presence of hyperpolarization-activated channels. D, A current-frequency plot showing high spike frequency adaptation of CRFR1-GFP in response to a series of depolarization currents. $\boldsymbol{E}$, A representative image, and summary table of single-cell reverse-transcription PCR results. F, Summary and location information for 50 identified PVN CRFR1-GFP neurons.

(Stern, 2001; Luther et al., 2002). Eleven percent (6 of 55) of CRFR1-GFP neurons displayed a weak LTS (small-amplitude hump; Fig. $3 A, B$, Type B), and 9\% (5 of 55) did not have a LTS or a transient outward rectification (Fig. 3A,B, Type C), electrical properties that define neurosecretory parvocellular neurons in rats. CRFR1-GFP neurons never displayed transient outward rectification, the electrical characteristic of magnocellular neurons (Luther and Tasker, 2000), consistent with our previous reports 

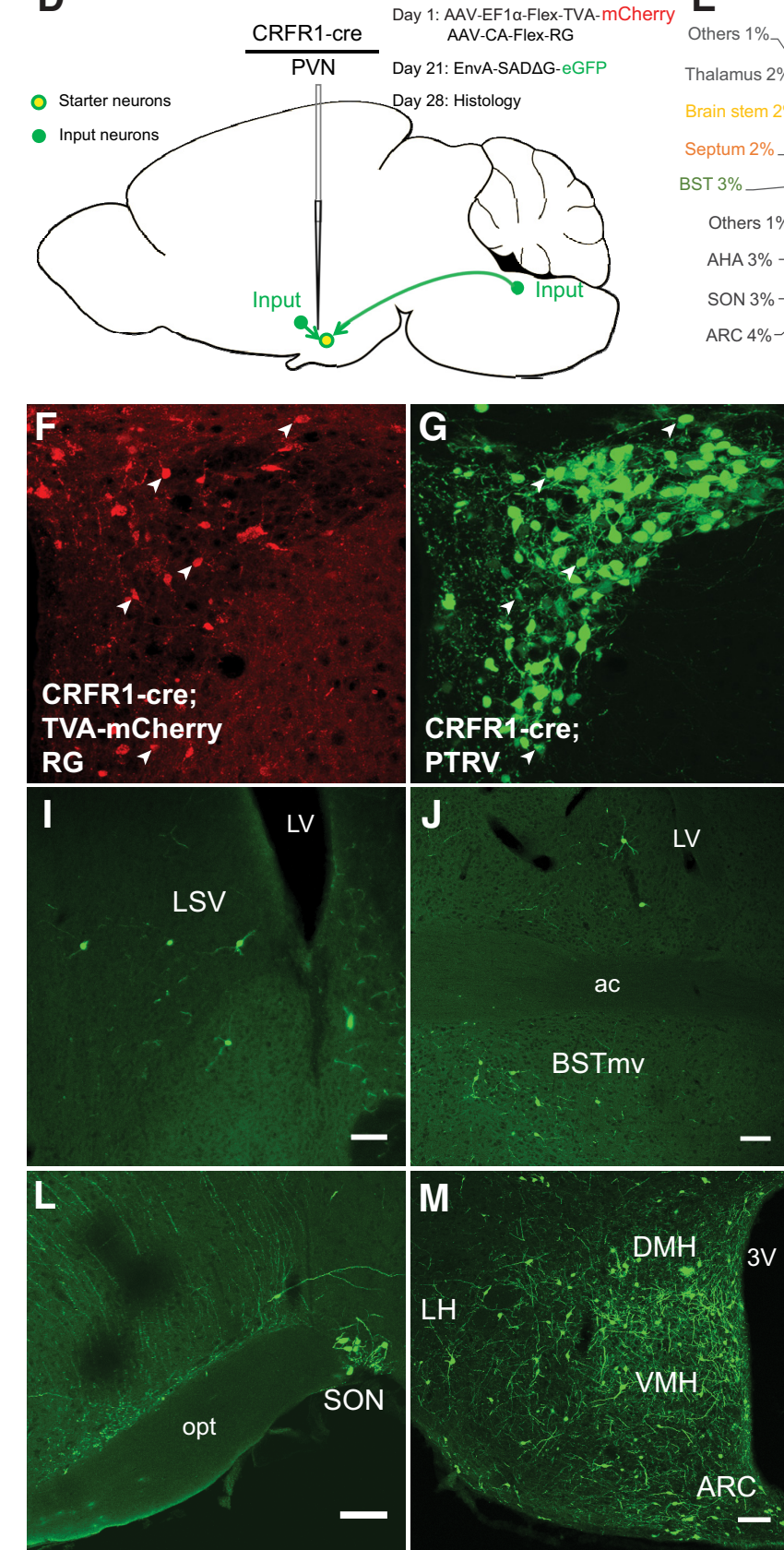

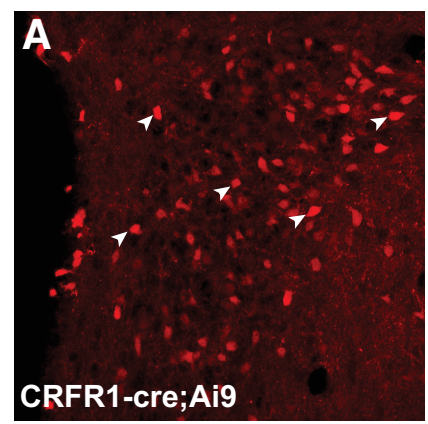

D

AAV-CA-Flex-RG

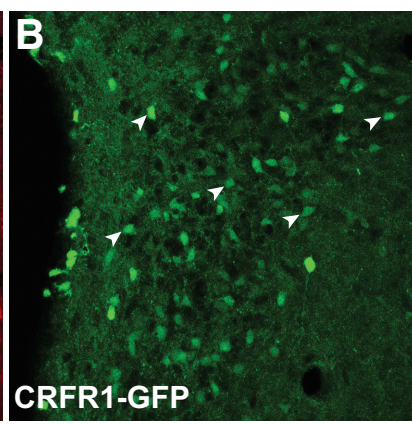

E

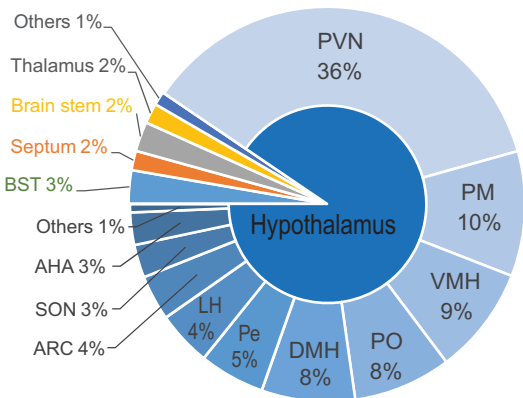

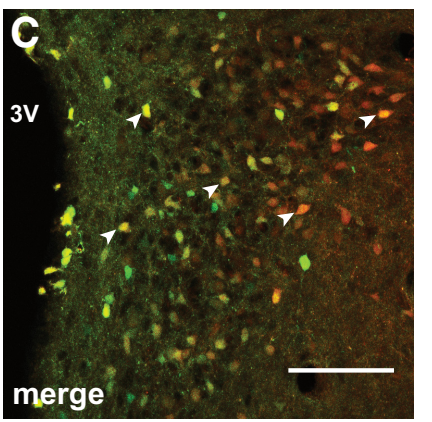

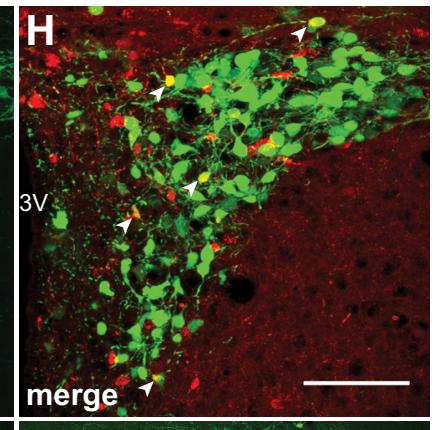

K

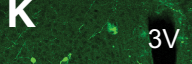

$3 \mathrm{~V}$

POA
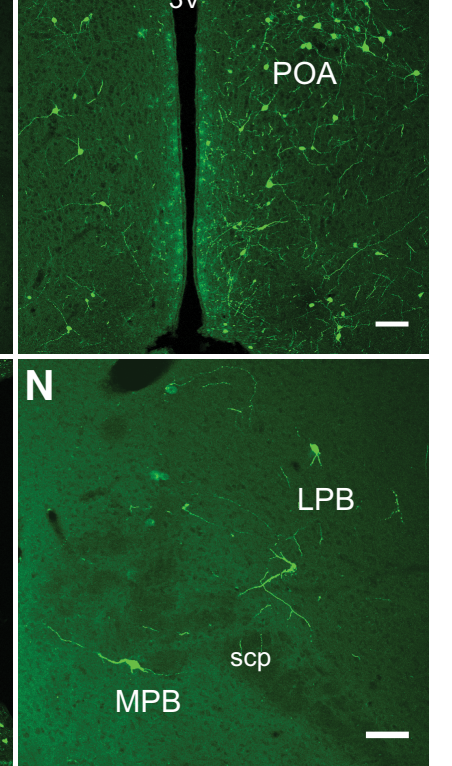

Figure 4. Mapping of monosynaptic inputs to PVN CRFR1 neurons. $\boldsymbol{A}, \boldsymbol{B}$, The expression pattern of tdTomato reporting Cre expression in CRFR1-GFP; (RFR1-Cre;Ai9 mice ( $\boldsymbol{A}$ ) is highly correlated with GFP expression from the validated CRFR1-GFP transgene ( $\boldsymbol{B})$. C, The merged image showing neurons expressing both reporters (arrowheads). Scale bar, $100 \mu \mathrm{m}$. $\boldsymbol{D}$, Schematic experimental design for pseudotyped rabies virus assisted monosynaptic retrograde tracing. E, Quantification of monosynaptic inputs to CRFR1 neurons in the PVN. Note that CRFR1 neurons receive $\sim 90 \%$ of their synaptic inputs from within the hypothalamus, especially from the PVN itself. PM, Premammillary nucleus; PO, preoptic area; Pe, periventricular nucleus; LH, lateral hypothalamus. $F$, Selective expression of TVA-mCherry in CRFR1 neurons within the PVN. G, Retrograde labeled presynaptic neurons within the PVN. $\boldsymbol{H}$, Merged image showing the presence of starter neurons, which initiate trans-synaptic infection to presynaptic neurons. Arrowheads indicate starter neurons, which express both TVA-mCherry and PTRV-eGFP. I- $\boldsymbol{N}$, Representative images of presynaptic neurons found in septum (LS and MS; $I)$, BST (J), POA (K), SON (L, bottom right,), DMH/VMH and ARC (M), and PB (N). Scale bar, $100 \mu \mathrm{m}$. 

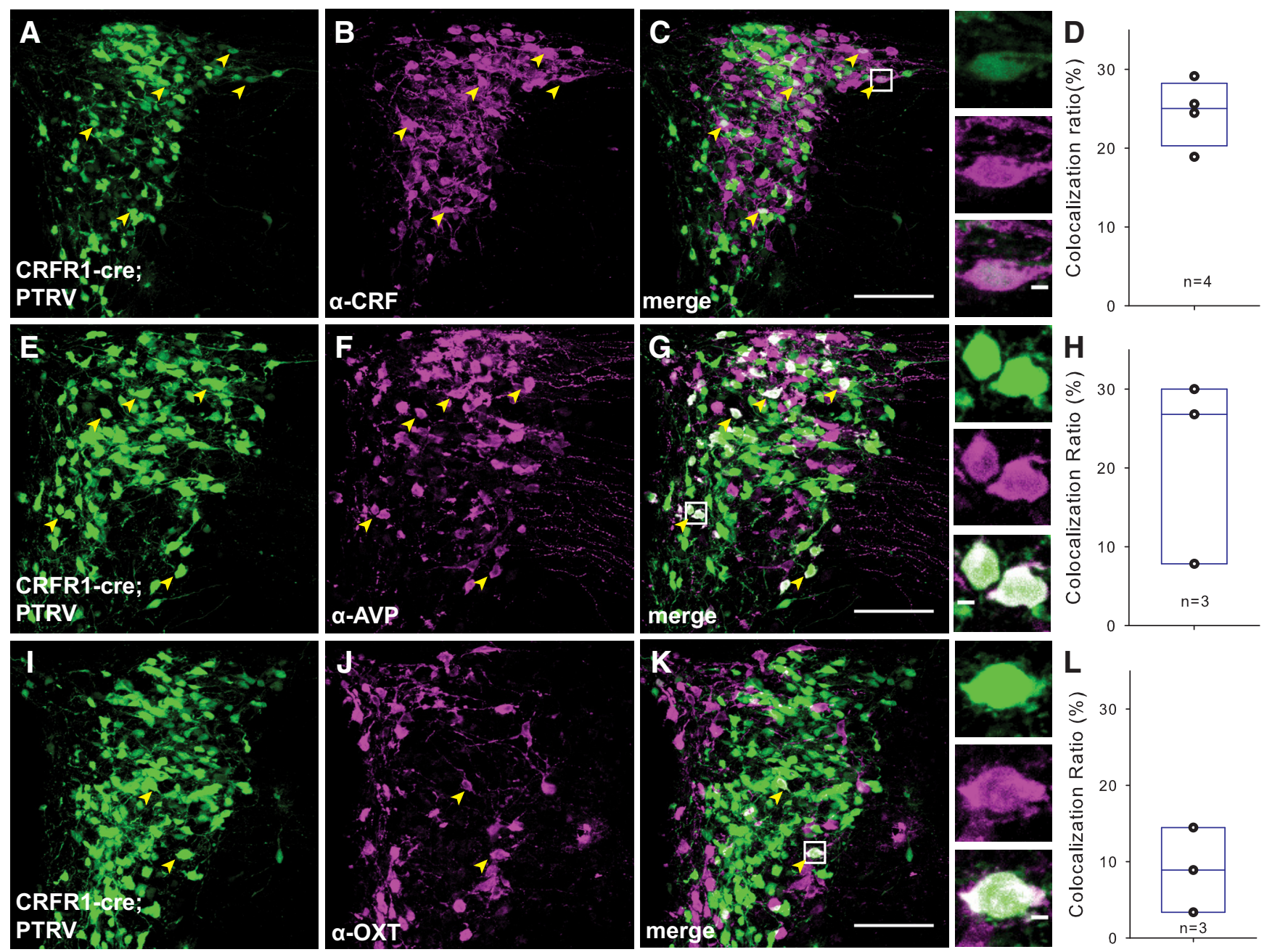

Figure 5. PVN CRFR1 neurons receive intra-PVN inputs. A-C, In PTRV-assisted mapping of CRFR1 neuron synaptic inputs, many of the presynaptic neurons (green, left) are positive for CRF (middle panels). The merged image shows that many CRF neurons make monosynaptic connections with CRFR1 neurons. Arrowheads point to the neurons that express eGFP and are immunoreactive for CRF. Insets, Higher-power micrographs of CRF-positive PTRV traced neurons. D, Quantification of $\mathrm{CRF}^{+}$input neurons. E-G, We also identified many presynaptic neurons (green, left) as positive for AVP (middle). The merged image shows the abundance of AVP ${ }^{+}$magnocellular neurons that are presynaptic to CRFR1 PVN neurons. $\boldsymbol{H}$, Quantification of AVP ${ }^{+}$input neurons. $I-\boldsymbol{K}$, Presynaptic $0 \mathrm{~T}^{+}$ neurons were also labeled by monosynaptic tracing, but were less frequent. L, Quantification of $0 T^{+}$input neurons. Scale bars: $100 \mu \mathrm{m}$ for $C, G, K ; 5 \mu \mathrm{m}$ for inserts.

that CRFR1 is not expressed by OT or AVP neurons (Ramot et al., 2017). Together, these data are consistent with the majority of CRFR1-GFP neurons in the PVN being preautonomic neurons, with a small proportion being neurosecretory parvocellular, and none being magnocellular PVN neurons.

After classifying PVN CRFR1-GFP neurons, we further characterized their electrical properties. In response to a hyperpolarization current, CRFR1-GFP neurons show a very small voltage sag at the beginning of the hyperpolarization (Fig. 3C; Sag ratio, $0.94 \pm 0.01 ; n=24$ ), suggesting that PVN CRFR1-GFP neurons express hyperpolarization-activated channels. When PVN CRFR1-GFP neurons are injected with a depolarizing current, they display a varied degree of spike frequency adaptation, as shown in a deflected current-frequency $(I-F)$ curve (Fig. 3D; SFA ratio, $3.54 \pm 0.43 ; n=21)$. In response to a $10-25 \mathrm{pA}$ depolarization current, the firing rate of CRFR1 neurons decreased, spikes became small, or the neurons became silent, entering a state called depolarization block (Fig. 3D; Luther and Tasker, 2000; Herman et al., 2014). This suggests that PVN CRFR1-GFP neurons are restrained from spiking very fast (only up to $\sim 12 \mathrm{~Hz}$ ) under physiological conditions.
Molecular properties of CRFR1 neurons in the hypothalamic paraventricular nucleus

To examine which neurotransmitters are released by CRFR1 neurons, we performed single-cell reverse transcription PCR (Fig. $3 E)$. From 50 identified PVN CRFR1-GFP neurons, we found that $42(84 \%)$ of the neurons express GAD1 and/or GAD2, 13 (26\%) express the vesicular GABA transporter (Vgat), and 27 (54\%) express vesicular glutamate transporter 2 (VgluT2; Fig. $3 F)$. VgluT2 ${ }^{+}$(putative glutamatergic) neurons are distributed throughout the anterior to posterior extent of the PVN, while $\mathrm{Vgat}^{+}$neurons are preferentially localized to the anterior and dorsal regions of the PVN (Fig. 3F). Interestingly, 21 (42\%) of the PVN CRFR1-GFP neurons express both GAD2 and VgluT2, and 8 (16\%) PVN CRFR1-GFP neurons express both Vgat and VgluT2, suggesting that these neurons might functionally release both neurotransmitters, as has been described in other systems (Root et al., 2014; Shabel et al., 2014; Yoo et al., 2016).

\section{Monosynaptic projections to CRFR1 neurons in the PVN}

To identify monosynaptic inputs to CRFR1 neurons in the PVN, we targeted CRFR1 neurons using PTRV tracing in CRFR1-Cre 


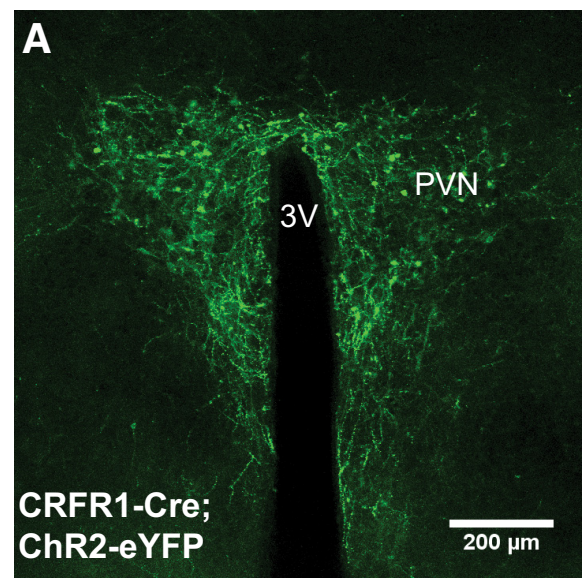

B

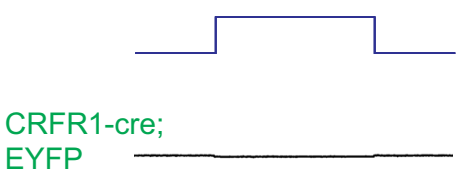
EYFP

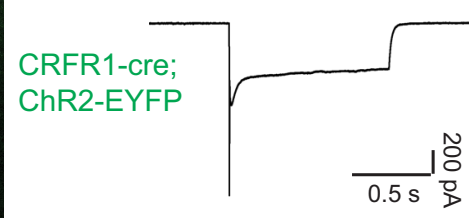

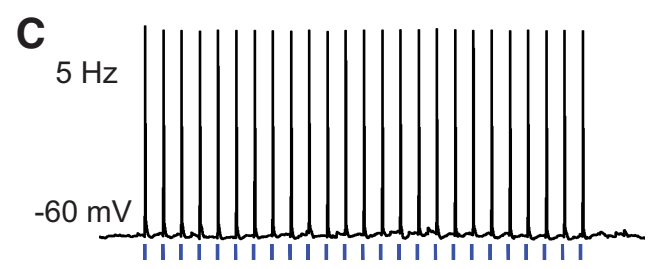

E

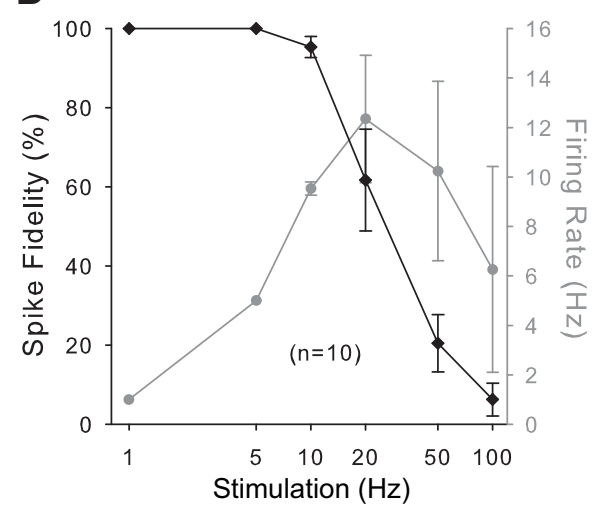

F Control

+ Bic
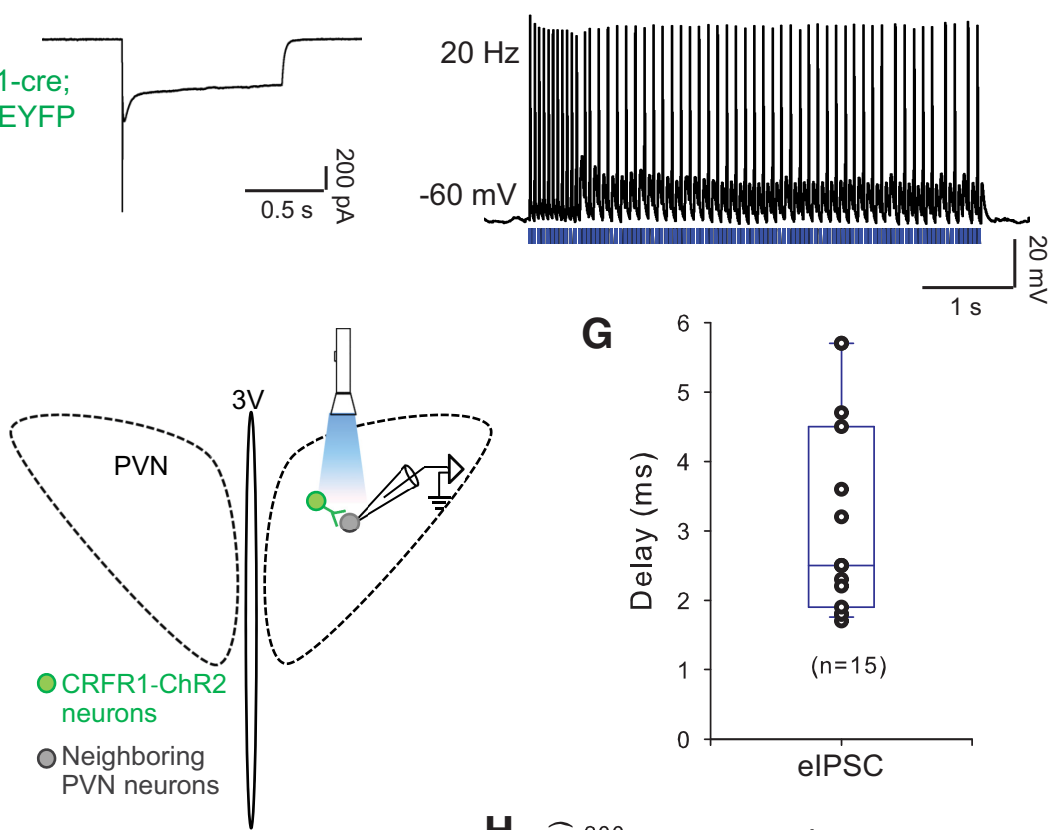

G

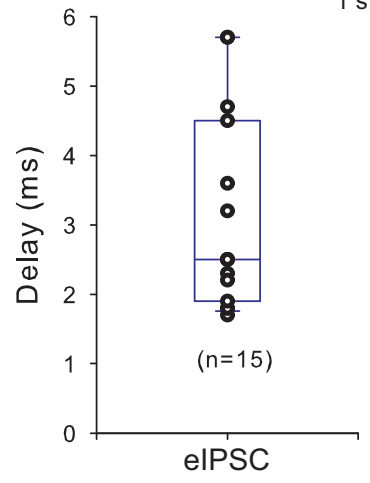

H

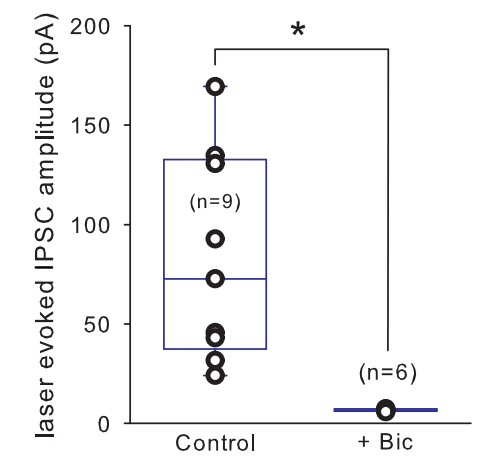

I Control + TTX
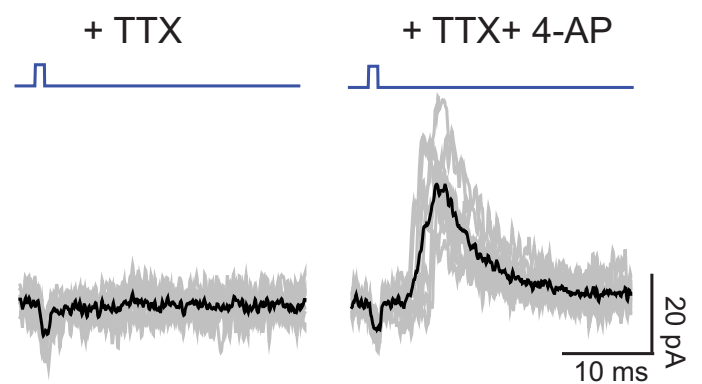
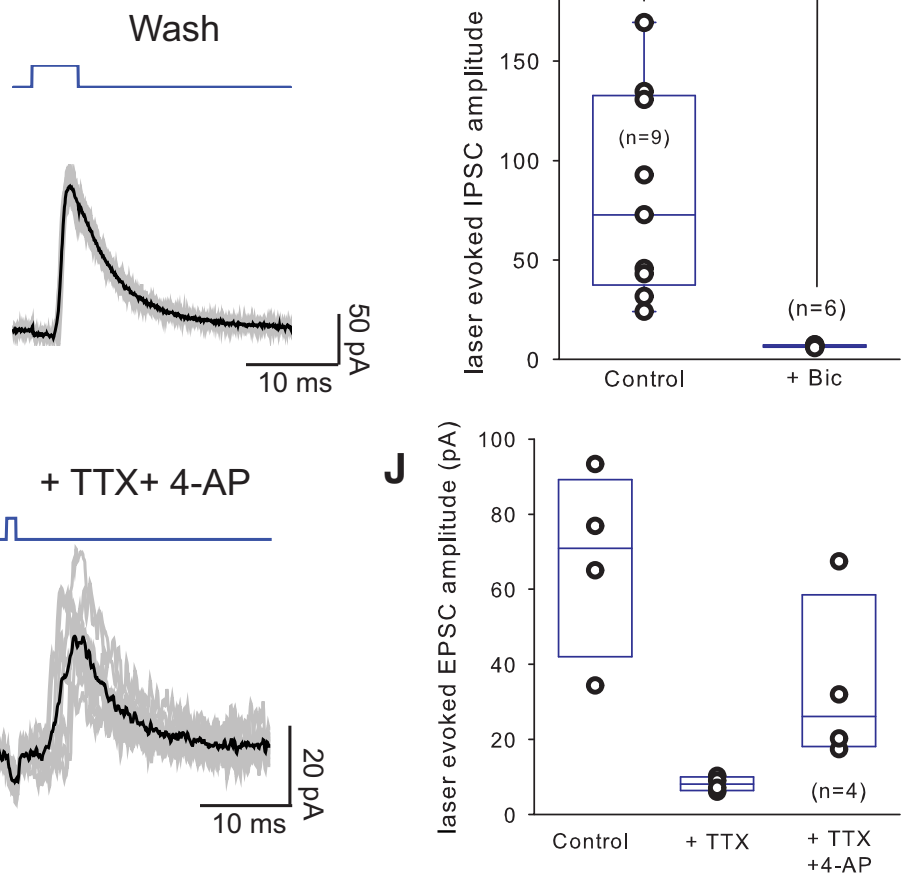

Figure 6. PVN-CRFR1 neurons make local projections within the nucleus. $\boldsymbol{A}$, Selective expression of ChR2-YFP in CRFR1-Cre neurons in the PVN. $\boldsymbol{B}$, Representative traces of photocurrents recorded in CRFR1 neurons. In CRFR1 neurons expressing ChR2, 1s photostimulation induced typical ChR2-mediated currents (bottom trace), whereas photostimulation with the same intensity and duration failed to induce photocurrents in the CRFR1 neurons infected with control virus (middle trace). C, Sample traces of action potential firing from a (RFR1-ChR2 neurons with 5 and $20 \mathrm{~Hz}$ optical stimulation (laser duration 1-5 ms), note the slowing of firing with $20 \mathrm{~Hz}$ stimulation. $\boldsymbol{D}$, Entrainment of CRFR1-ChR2 neurons to direct optical stimulation: percentage change in spike fidelity and ChR2-mediated CRFR1 neurons firing $(n=10)$. $E$, Schematic experimental design. Laser-evoked postsynaptic responses were recorded in neighboring PVN neurons. (F) Representative traces from a neighboring neuron in the PVN, showing laser-evoked IPSCs, which are blocked by Bic and are restored after washout. Blue, Photostimulation; gray lines, individual traces; dark lines, averaged traces. G, Delay of laser-evoked elPSCs from PVN neurons $(n=15)$. $\boldsymbol{H}$, Summary histogram of elPSCs in the PVN, which is blocked by selective GABA $A_{A}$ antagonist bicuculline $(40 \mu m ; n=6 ; p<0.05$, paired Student's $t$ test). I, Representative trace of a laser-evoked IPSC, which is blocked by TTX and rescued by 4-AP. Blue, Photostimulation; gray lines, individual traces; dark lines, averaged traces. J, Summary histogram of elPSCs blocked by TTX and rescued by 4-AP $(n=4) .{ }^{*} p<0.05$. 
mice. Faithful expression of CRFR1-Cre in CRFR1-GFP neurons was verified by creating CRFR1-GFP; CRFR1-Cre; Ai9 mice and comparing the expression patterns of GFP and tdTomato. In these mice, we observed a very similar expression pattern of GFP and tdTomato (Fig. $4 A-C$ ), indicating that CRFR1-Cre is expressed in the same population of neurons in the PVN as CRFR1-GFP. Helper viruses (AAV-EFla-FLEX-TVA-mCherry and AAVCA-FLEX-G, 1:1 mixture) were stereotaxically injected in CRFR1-Cre mice, which allows subsequent infection and packaging of PTRV (EnvA-SAD $\Delta$ GeGFP) by CRFR1 ${ }^{+}$neurons in the PVN (Fig. 4D). PTRV then "jumps" one retrograde synapse to infect monosynaptically connected cells (Wickersham et al., 2007; Wall et al., 2010; Watabe-Uchida et al., 2012). "Starter" neurons, which are infected both by helper viruses and PTRV, are labeled with red and green fluorescence, while neurons that make monosynaptic inputs onto CRFR1 neurons are labeled with only green fluorescence (Fig. $4 F-H)$. In Cre-negative (wt) mice with identical viral injections, no neurons were visible expressing either mCherry or eGFP $(n=3)$. Using this technique, we found that CRFR1 neurons receive the vast majority of their synaptic inputs from within the PVN or from other hypothalamic nuclei ( 90\%; Fig. 4E). CRFR1 neurons also receive monosynaptic inputs from previously identified longrange sources of afferent projections to the PVN, such as the lateral septum (LS) and medial septum (MS; Fig. 4I), bed nucleus of stria terminalis (BST; Fig. 4J), preoptic area (POA; Fig. $4 K$ ), supraoptic nucleus (SON; Fig. $4 L$ ), dorsomedial hypothalamus (DMH) and ventromedial hypothalamus (VMH; Fig. $4 M$ ), arcuate nucleus (ARC; Fig. 4M), and brainstem (Fig. 4N). These data demonstrate that CRFR1 neurons in the PVN receive both local and long-range synaptic connections.

To further examine the molecular identity of neurons presynaptic to CRFR1 neurons in the PVN, we stained sections of PTRVtraced PVN-CRFR1 neurons for CRF, AVP, and OT. Within the PVN, $24.5 \pm 2.1 \%(n=4)$, monosynaptically labeled neurons express CRF (Fig. $5 A-D$ ), suggesting that synapses occur between CRF and CRFR1 neurons in the PVN, consistent with immunohistochemical observations (Fig. 1D-G). In addition, we observed monosynaptic connections to CRFR1 neurons from AVP (21.5 $\pm 6.9 \%$, $n=3$; Fig. $5 E-H)$ and OT $(8.9 \pm 3.2 \%, n=3$; Fig. $5 I-L)$ neurons. These data demonstrate that CRFR1 PVN neurons are highly interconnected with other neuron types within the PVN. Together with long-range connections, hypothalamic connections, and intra-PVN connections, PVN-CRFR1 neurons are positioned to integrate multiple aspects of PVN signaling.

\section{CRFR1 neurons synapse in the PVN}

Next, we investigated which neurons in the PVN are postsynaptic to CRFR1 neurons using channelrhodopsin-2-assisted circuit map- ping (Petreanu et al., 2007). We expressed ChR2 in CRFR1 neurons by injecting the PVN of CRFR1-Cre animals with Cre-dependent ChR2-EYFP AAV (AAV2-EF1a-DIO-hChR2(H134R)-EYFP; Fig. $6 A$ ). After infection, we were able to evoke photocurrents (peak, $1419.08 \pm 149.83 \mathrm{pA}$; steady state, $278.30 \pm 38.35 \mathrm{pA} ; n=6$; Fig. $6 B$, bottom trace) in infected neurons using a $473 \mathrm{~nm}$ blue laser, while no photocurrents were observed in mice infected with control virus $(n=12$; Fig. $6 B$, middle trace). In addition, trains of $473 \mathrm{~nm}$ laser pulses drove CRFR1 neuronal firing reliably (3.5-5 mW, 1-5 ms) up to $\sim 12 \mathrm{~Hz}$. At $20 \mathrm{~Hz}$, we observed substantial failures (Fig. 6C,D), consistent with the relatively high-spike frequency adaptation and the curved $I-F$ plot with current injections observed when recording from CRFR1-GFP neurons (Fig. 3D), in sharp contrast to those observed in CRF neurons, which can fire up to $20 \mathrm{~Hz}$. In this configuration (optically driving CRFR1 neuron firing while recording from nearby neurons within the PVN; Fig. 6E), we observed evoked IPSCs (eIPSCs) in 22 of 111 (20\%) neurons (Fig. 6F-J), with an average delay of $3.1 \pm 0.36 \mathrm{~ms}$ (Fig. $6 G$ ). eIPSCs had an average reversal potential of $-75.40 \pm 1.58 \mathrm{mV}(n=4)$ and could be blocked by the selective $\mathrm{GABA}_{\mathrm{A}}$ receptor antagonist bicuculline $(40 \mu \mathrm{M}$; Fig. $6 \mathrm{~F}, \mathrm{H}$; from $87.53 \pm 23.32 \mathrm{pA}$ in aCSF to $6.70 \pm 0.23 \mathrm{pA}$ in Bic; $t_{(5)}=3.46$, $p=0.018$, paired $t$ test; voltage clamp $(\mathrm{VC})=-60 \mathrm{mV}$ or $-40 \mathrm{mV}$ ), then recovered after washout (see Fig. $6 F$ ). In addition, laser-evoked IPSCs were blocked by TTX $(0.5 \mu \mathrm{M}$, voltage-gated sodium channel 

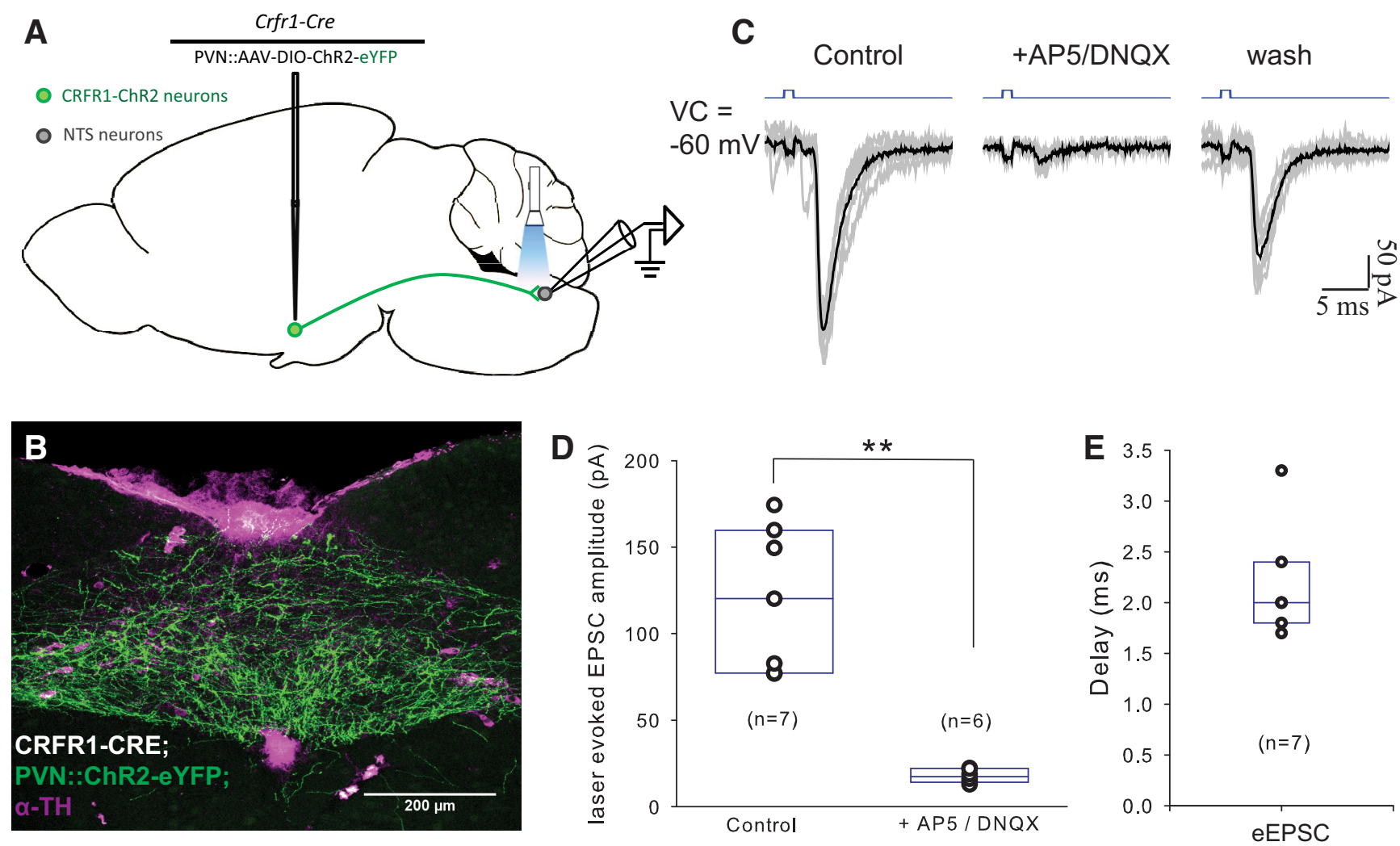

Figure 8. PVN-CRFR1 neurons make long-range projections to NTS. A, Schematic of the experimental design. B, A micrograph of the NTS from a CRFR1-Cre mouse injected with ChR2 into the PVN. Green, CRFR1-ChR2-YFP; blue, anti-tyrosine hydroxylase (TH) staining. C, Representative traces of laser-evoked EPSCs in a NTS neuron, which are blocked by AP5/DNQX and restored after washout. Gray lines, Individual traces; dark lines, averaged traces. D, Summary histogram of laser-evoked EPSCs in the NTS, which are blocked by AP5/DNQX ( $n=6, p<0.05$, paired $t$ test). E, Plot of the delay before an eEPSC from light onset in NTS neurons $(n=7) .{ }^{* *} p<0.01$.

blocker), and partially rescued by 4 -AP ( $1 \mathrm{mM}$, nonselective potassium channel blocker; Fig. $6 I, J)$, confirming that CRFR1 neurons make inhibitory monosynaptic connections within the PVN. We did not observe any evoked EPSCs (eEPSCs) when we recorded in this configuration within the PVN. Of the 22 neurons that received synaptic connections from PVN-CRFR1 neurons, 10 displayed characteristics of neurosecretory parvocellular neurons (CRF or TRH; 26 total parvocellular neurons recorded), 4 of magnocellular neurons (AVP or OT; 46 total magnocellular neurons recorded), and 8 of non-neurosecretory preautonomic neurons (39 total preautonomic neurons recorded; (Luther and Tasker, 2000; Stern, 2001; Luther et al., 2002). Based on these observations, we conclude that CRFR1 neurons make exclusively GABAergic synapses locally on multiple cell types within the PVN.

\section{Mapping the projections of PVN-CRFR1 neurons}

To identify long-range synaptic targets of PVN-CRFR1 neurons, we selectively expressed presynaptically localized synaptophysinenhanced yellow fluorescent protein (syn-eYFP; AAV-FLEXsynaptophysin-eYFP) in PVN-CRFR1 neurons and looked at presynaptic terminal fields identified by syn-eYFP fluorescence (Fig. $7 A, B$ ). We observed dense syn-eYFP-rich terminal fields in the LS (Fig. 7C), BST (Fig. 7D), periaqueductal gray (PAG; Fig. $7 E$ ), parabrachial nucleus (PB) and locus ceruleus (LC; Fig. $7 F$ ), ventromedial medulla (VLM; Fig. 7G), and NTS (Fig. 7H). These data are consistent with electrophysiological data that a majority of CRFR1 neurons are preautonomic neurons that project to brainstem nuclei (Fig. 1E; Stern, 2001; Li et al., 2002).

\section{CRFR1 neurons make long-range excitatory synapses in the NTS}

Using the same optogenetic strategy we used to identify local connections, we examined long-range connections made by PVN-CRFR1 neurons (Fig. 8A). In CRFR1-cre animals PVNinjected with Cre-dependent ChR2-YFP-encoding virus, we could observe dense ChR2-eYFP fibers in the NTS (Fig. 8B). Optical stimulation of PVN-CRFR1-ChR2 axonal terminals in NTS evoked eEPSCs in 19 of 43 (44\%) neurons, with an average delay of $2.17 \pm 0.21 \mathrm{~ms}$ (Fig. $8 E$ ) and an average amplitude of $120.05 \pm$ 15.79 pA (Fig. $8 D ; n=7$; VC $=-60 \mathrm{mV}$ ). eEPSCs were blocked by the ionotropic glutamatergic blockers DNQX $(20 \mu \mathrm{M})$ and AP5 (50 $\mu \mathrm{M}$; Fig. 8C,D; from $113.44 \pm 16.97 \mathrm{pA}$ in aCSF to $17.77 \pm 1.60 \mathrm{pA}$ in AP5/DNQX; $t_{(5)}=5.83, p=0.002$, paired $t$ test; $\mathrm{VC}=-60 \mathrm{mV}$ ) and recovered after washout with aCSF (Fig. $8 C$ ). The short latency of eEPSCs and their blockade with glutamate receptor antagonists indicate that these connections are monosynaptic glutamatergic synapses. We did not observe eIPSCs in NTS neurons, suggesting that PVN-CRFR1 neurons make exclusively glutamatergic synapses in the NTS, in contrast to local synapses made by CRFR1 neurons, which are GABAergic (Fig. 6F, H).

PVN-CRFR1 neurons are required for HPA axis control To evaluate the role of PVN-CRFR1 neurons in HPA axis regulation, we used DTR-mediated conditional cell ablation to deplete PVNCRFR1 neurons (Saito et al., 2001; Buch et al., 2005). Injection of CRFR1-Cre mice in the PVN with Cre-dependent DTR-encoding 
AAVs (AAV-EF1a-FLEX-DTR-P2A-EYFP) achieved expression of DTR in CRFR1 neurons of the PVN (Fig. 9A). Following a single dose of DT, CRFR1 neurons were selectively deleted (CRFR1-DTR mice; Fig. 9B). CRFR1-cre mice do not have a baseline HPA axis phenotype when compared with their wild-type littermates $\left(F_{(1,60)}=1.15, p=\right.$ 0.29, two-way ANOVA; data not shown). However, after ablation of PVN-CRFR1 neurons with DT, we observed a significant increase in circulating corticosterone levels over the course of a $2 \mathrm{~h}$ immobilization stress challenge $\left(F_{(1,95)}=15.08, p<\right.$ 0.001, two-way ANOVA; Fig. 9C). Post hoc statistical analysis of differences at individual time point revealed that CRFR1DTR mice have elevated corticosterone levels during stress application compared with their unablated controls (CRFR1-cre mice injected with AAV-DIO-eGFP and given the same dosage of DT; 60 min: control, $140.8 \pm 10.5 \mathrm{ng} / \mathrm{ml}, n=9$; DTR, $150.0 \pm 20.2 \mathrm{ng} / \mathrm{ml}, n=12 ; t_{(19)}=2.29$, $p=0.03$, Holm-Sidak method). Furthermore, corticosterone levels fell more slowly in CRFR1-DTR mice. Two hours after release from immobilization stress, CRFR1-DTR mice had significantly higher levels of circulating corticosterone (control: $78.5 \pm 7.4 \mathrm{ng} / \mathrm{ml}, n=9$; DTR: $150.0 \pm 20.2 \mathrm{ng} / \mathrm{ml}, n=12 ; t_{(19)}=2.53$, $p=0.01$, Holm-Sidak method; Fig. 9C). Given the elevations in corticosterone levels at multiple time points of a stress challenge after removal of CRFR1 PVN neurons, we conclude that PVN-CRFR1 neurons are required as an inhibitory mechanism that appropriately controls HPA axis activity during the stress response.

\section{Discussion}

We have characterized a novel population of neurons in the PVN that express CRFR1 receptors and respond to locally released CRF. CRFR1 neurons then feedback to influence CRF neuron activity and coordinate activity across the PVN between different cell types. CRF neurons, as initiators of the HPA axis, send their primary projections to the median eminence, where they release CRF to the portal system to activate ACTH release by pituitary corticotropes (Vale et al., 1981). However, experiments presented here suggest that CRF is also released by PVN neurons within the PVN, either by somatodendritic release or collateral axonal projections. Somatodendritic release of neuropeptides in the PVN is not unprecedented. Intra-PVN signaling has been shown both within the same neural population (Lambert et al., 1993; Oliet et al., 2007; Iremonger and Bains, 2009; Wamsteeker Cusulin et al., 2013b; Haam et al., 2014) as well as between different populations (Son et al., 2013), mediated by somatodendritic release of neuropeptides from AVP and OT neurons. This study describes intra-PVN signaling by CRF, which func- tions to coordinate the activity of the HPA axis as well as hypothalamic-autonomic systems.

\section{Electrophysiological signature of CRFR1 neurons}

CRFR1-GFP neurons do not express AVP or OT, only a very small percentage uptake circulating fluorogold and only $7 \%$ are CRF positive, suggesting that the majority of PVN-CRFR1 neurons are non-neurosecretory, preautonomic neurons (Ramot et al., 2017). Consistent with this, we found that the majority of PVN-CRFR1 neurons express a low threshold spike, the electrophysiological signature of preautonomic neurons in rats (Stern, 2001; Luther et al., 2002; Lee et al., 2008). In addition, PVNCRFR1 neurons project to the NTS and PB, brainstem nuclei central to autonomic regulation (Figs. 7, 8). Therefore, we propose that CRFR $1^{+}$neurons in the PVN are a subtype of previously classified "preautonomic" neurons. Optogenetic activation of CRFR1 neurons evokes spiking up to $12 \mathrm{~Hz}$ (Fig. $6 C, D$ ), which is significantly slower than the maximum optogenetically driven action potential frequency in CRF neurons of $20 \mathrm{~Hz}$ (Wamsteeker Cusulin et al., 2013a). This difference is most likely due to the intrinsic properties of CRFR1 neurons compared with CRF neurons, although failures at 


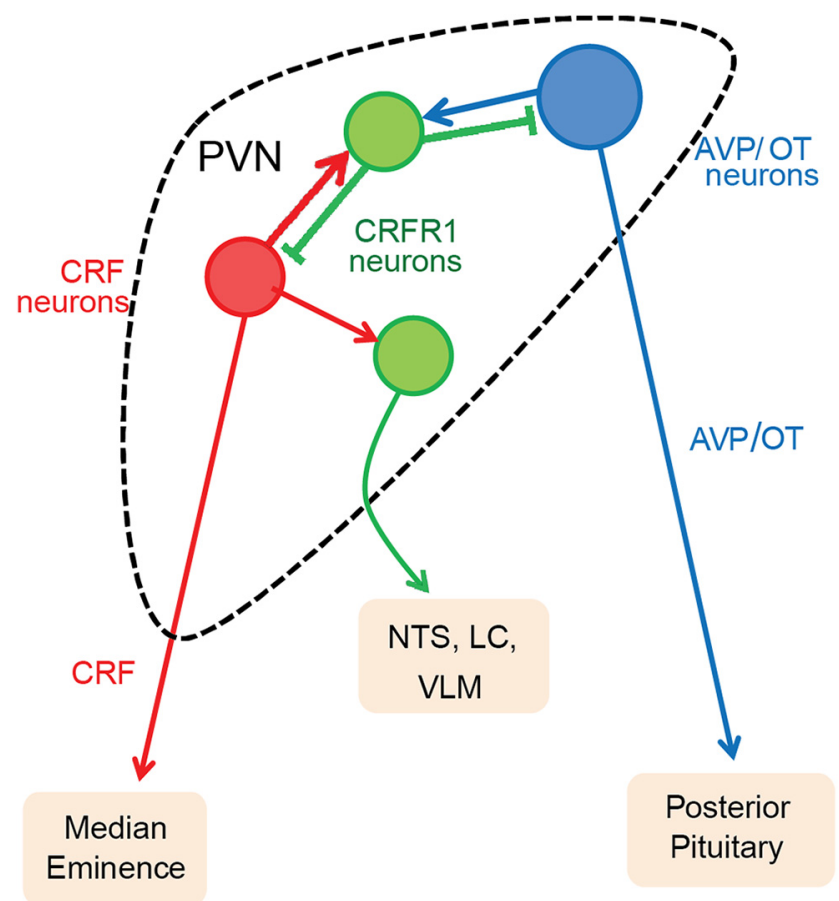

Figure 10. Proposed model for intra-PVN CRF signaling. CRFR1 neurons (green) receive monosynaptic inputs from both CRF neurons (red) and AVP neurons (blue) from within the PVN, together with other hypothalamic inputs, to coordinate PVN activity during stress. CRFR1 neurons make inhibitory synapses onto CRF neurons, functioning as a synaptic negative feedback on HPA axis activity. CRFR1 neurons also synapse on other resident PVN neurons to coordinate activity of CRF neurons with other endocrine axes. CRFR1 neurons also send excitatory longrange projections to potentiate autonomic tone during stress.

higher stimulation frequencies is possibly due to the kinetics of ChR2 (Boyden et al., 2005).

One specific electrophysiological signature of PVN-CRFR1 neurons is their excitation by CRF. CRF binding likely increases the excitability of CRFR1 PVN neurons by enhancing hyperpolarization-activated cation currents via $\mathrm{HCN}$ channels as has been shown in rat hypothalamic PVN neurons (Qiu et al., 2005). In addition, CRFR1 can couple with either the Gs-cAMPPKA pathway (Perrin et al., 1993) or the Gq-PLC-PKC pathway (Dautzenberg and Hauger, 2002; Blank et al., 2003) to alter excitability. Although PVN neurons have been more thoroughly characterized morphologically and electrophysiologically in rats (Armstrong et al., 1980; Swanson and Kuypers, 1980; Swanson and Sawchenko, 1980; Luther and Tasker, 2000; Stern, 2001; Luther et al., 2002; Simmons and Swanson, 2009), genetic strategies in the mouse have revealed the existence of this novel population of CRFR1 neurons in the PVN. Given the increasing availability of transgenic rat strains (e.g., rat CRFR1-cre), we will likely be able to identify this same population of CRFR ${ }^{+}$neurons in the rat PVN. Future studies will reveal additional electrophysiological properties based on molecular classification, as well as key intracellular signaling pathways that are important for excitation in response to CRF.

\section{The nature of the CRF/CRFR1 connections in the PVN}

PVN-CRFR1 neurons are activated by CRF, and this activation is blocked by selective CRFR1 antagonists, indicating that CRFR1 receptors are functional and excitatory in PVN-CRFR1 neurons (Fig. 1). Moreover, optical activation of CRF neurons causes activation of neighboring CRFR1 neurons in the PVN, indicating that CRF inputs from within the PVN are sufficient to activate
CRFR1 neurons (Fig. 2). By virtue of the positioning of CRFR1 neurons in close proximity to CRF neurons and visible physical interaction sites between these neurons (Fig. 1), they could signal either through wired synapses or volume transmission of neuropeptides. We recorded from CRFR1 neurons while optogenetically activating CRF neurons and only saw evoked EPSCs in 1 of 43 (2\%) CRFR1 neurons, while 13 of 21 (62\%) CRFR1 neurons displayed increased firing in response to CRF neuron optical activation (1-20 Hz) even when glutamatergic and GABAergic transmission are blocked (Fig. $2 F$, top and middle). This activation is eliminated by the selective CRFR1 antagonist Antalarmin (Fig. $2 F$, bottom), indicating that communication between CRF and CRFR1 neurons is occurring via CRF, and not by fast chemical synapses. It is surprising that we fail to see a stronger excitatory effect with $20 \mathrm{~Hz}$ optical stimulation compared with $1 \mathrm{~Hz}$, in contrast to observations made in recordings from magnocellular neurons in the PVN and SON (Gainer et al., 1986; de Kock et al., 2003; Dayanithi et al., 2012). However, our understanding about the optimal optogenetic stimuli to release CRF remains limited, and other unknowns within this system might also contribute to this discrepancy. While electrophysiological experiments suggest that CRF is the relevant signaling molecule between CRF and CRFR1 neurons in the PVN, when we trace synaptic connectivity using rabies viral tracing, which requires a tight synapse to transduce the virus (Ugolini, 1995), we observe retrograde trans-synaptic labeling, indicating that CRF neurons do make synapses onto CRFR1 neurons in the PVN. We also see points of contact between these two types of neurons using immunofluorescent labeling, and CRFR1-apposed CRF fibers are often positive for CGA and CRF, suggesting that CRF is released at these appositions by large, dense core vesicles (Fig. 1D-G). Future studies, using either ultrastructural resolution electron microscopy or dual electrophysiological recordings are needed to further clarify the nature of this connection.

\section{Intra-PVN CRF signaling influences HPA axis activity}

CRF neurons excite CRFR1 neurons, which send recurrent GABAergic synapses, establishing a novel local microcircuit in the PVN that we propose functions to provide inhibition to CRF neurons, likely in the context of persistent CRF neuron activity. The functional importance of this microcircuit is supported by our experiments in which ablation of CRFR1 neurons in the PVN elevates HPA axis activity (Fig. 9), suggesting that this mechanism is required for negative feedback to limit HPA axis activity. In our recent work, we found that selective deletion of CRFR1 within the PVN (Sim1-cre; CRFR1fl/fl) decreases basal corticosterone levels after chronic social defeat stress (Ramot et al., 2017). We suggest that the discrepancy in the polarity of the CRFR1 neuron influence on HPA axis activity is due to the depolarizing shift in the reversal potential for $\mathrm{GABA}_{\mathrm{A}}$-mediated synaptic events that occurs following chronic stress (Hewitt et al., 2009; Gao et al., 2017). After chronic stress, local GABAergic connections become depolarizing, functioning to maintain HPA axis tone (Ramot et al., 2017).

\section{CRFR1 neurons are poised to integrate activity across the hypothalamus}

Neurons in the PVN receive their inputs from diverse brain regions, such as the BST, AHA, medial preoptic area (MPO), $\mathrm{LH}$, suprachiasmatic nucleus or nuclei (SCN), ARC, DMH/VMH, PAG, PB, LC, and NTS (Cunningham and Sawchenko, 1988; Liposits and Paull, 1989; Boudaba et al., 1996, Boudaba et al., 1997; Li et al., 1998; Csáki et al., 2000; Wittmann, 2008; Ulrich- 
Lai et al., 2011; Ziegler et al., 2012). In our rabies viral tracing studies, we found that CRFR1 neurons in the PVN receive $\sim 90 \%$ of their monosynaptic inputs from within the hypothalamus ( $\sim 90 \%$; Fig. 4), of which over one-third are from other neurons within the PVN, indicating that CRFR1 neurons likely function to integrate activity within the hypothalamus, especially within PVN itself. Indeed, intrahypothalamic monosynaptic connections to PVN play an important role in energy homeostasis (Atasoy et al., 2012; Wu et al., 2015; Fenselau et al., 2017) and sympathetic control of cardiovascular function (Son et al., 2013; Dergacheva et al., 2017). Within the PVN, CRFR1 neurons may function to coordinate activity between CRF and AVP neurons, consistent with the dramatic synergism of CRF and AVP in evoking ACTH release by pituitary corticotropes (Buckingham, 1982; Salata et al., 1988). CRFR1 neurons also likely serve an important function in autonomic circuits that transit the PVN, given that majority of CRFR1 neurons are preautonomic neurons.

PVN-CRFR1 neurons express Vgat and/or VgluT2, suggesting that they can release GABA, glutamate, or both neurotransmitters to their downstream partners (Fig. 3E,F). Using optogenetic tools, we found that intra-PVN projections are exclusively GABAergic (Fig. 6), and long-range projections to NTS are exclusively glutamatergic (Fig. 8), indicating that the valence of efferent connections made by PVN-CRFR1 neurons is spatially defined. Based on tracing and connectivity experiments, we propose a model in which, during a stress response when CRF neurons are highly active, CRF is released locally in the PVN to activate CRFR1 neurons (Fig. 10). These neurons feed back onto CRF neurons to inhibit their activity, functioning as a local negative feedback microcircuit to limit HPA axis hyperactivity. In addition, in response to CRF, CRFR1 neurons excite downstream autonomic nuclei to potentiate autonomic tone, which might be critical during an extended stressor. Given the high degree of connectivity (both afferent and efferent) with local and long-range targets, it is likely that CRFR1 PVN neurons function in additional integration and modulation capacities. In these ways, CRFR1 neurons function to help orchestrate the coordinated endocrine and autonomic output of the PVN.

\section{References}

Armstrong WE, Warach S, Hatton GI, McNeill TH (1980) Subnuclei in the rat hypothalamic paraventricular nucleus: a cytoarchitectural, horseradish peroxidase and immunocytochemical analysis. Neuroscience 5:19311958. CrossRef Medline

Atasoy D, Betley JN, Su HH, Sternson SM (2012) Deconstruction of a neural circuit for hunger. Nature 488:172-177. CrossRef Medline

Biag J, Huang Y, Gou L, Hintiryan H, Askarinam A, Hahn JD, Toga AW, Dong HW (2012) Cyto- and chemoarchitecture of the hypothalamic paraventricular nucleus in the C57BL/6J male mouse: a study of immunostaining and multiple fluorescent tract tracing. J Comp Neurol 520:633. CrossRef Medline

Blank T, Nijholt I, Grammatopoulos DK, Randeva HS, Hillhouse EW, Spiess J (2003) Corticotropin-releasing factor receptors couple to multiple G-proteins to activate diverse intracellular signaling pathways in mouse hippocampus: role in neuronal excitability and associative learning. J Neurosci 23:700-707. Medline

Boudaba C, Szabó K, Tasker JG (1996) Physiological mapping of local inhibitory inputs to the hypothalamic paraventricular nucleus. J Neurosci 16:7151-7160. Medline

Boudaba C, Schrader LA, Tasker JG (1997) Physiological evidence for local excitatory synaptic circuits in the rat hypothalamus. J Neurophysiol 77: 3396-3400. CrossRef Medline

Boyden ES, Zhang F, Bamberg E, Nagel G, Deisseroth K (2005) Millisecondtimescale, genetically targeted optical control of neural activity. Nat Neurosci 8:1263-1268. CrossRef Medline

Brown MR, Fisher LA (1985) Corticotropin-releasing factor: effects on the autonomic nervous system and visceral systems. Fed Proc 44:243-248. Medline
Buch T, Heppner FL, Tertilt C, Heinen TJ, Kremer M, Wunderlich FT, Jung S, Waisman A (2005) A Cre-inducible diphtheria toxin receptor mediates cell lineage ablation after toxin administration. Nat Methods 2:419-426. CrossRef Medline

Buckingham JC (1982) Potentiation of hypothalamic corticotropin releasing activity by vasopressin: studies in the Brattleboro rat. Ann N Y Acad Sci 394:580-586. CrossRef Medline

Chan W, Costantino N, Li R, Lee SC, Su Q, Melvin D, Court DL, Liu P (2007) A recombineering based approach for high-throughput conditional knockout targeting vector construction. Nucleic Acids Res 35:e64. CrossRef Medline

Chen Y, Molet J, Gunn BG, Ressler K, Baram TZ (2015) Diversity of reporter expression patterns in transgenic mouse lines targeting corticotropin-releasing hormone-expressing neurons. Endocrinology 156:4769-4780. CrossRef Medline

Chrousos GP (2000) The role of stress and the hypothalamic-pituitaryadrenal axis in the pathogenesis of the metabolic syndrome: neuroendocrine and target tissue-related causes. Int J Obes Relat Metab Disord 24 [Suppl 2]:S50-S55. Medline

Contarino A, Dellu F, Koob GF, Smith GW, Lee KF, Vale W, Gold LH (1999) Reduced anxiety-like and cognitive performance in mice lacking the corticotropin-releasing factor receptor 1. Brain Res 835:1-9. CrossRef Medline

Csáki A, Kocsis K, Halász B, Kiss J (2000) Localization of glutamatergic/ aspartatergic neurons projecting to the hypothalamic paraventricular nucleus studied by retrograde transport of $[3 \mathrm{H}] \mathrm{D}$-aspartate autoradiography. Neuroscience 101:637-655. CrossRef Medline

Cunningham ET Jr, Sawchenko PE (1988) Anatomical specificity of noradrenergic inputs to the paraventricular and supraoptic nuclei of the rat hypothalamus. J Comp Neurol 274:60-76. CrossRef Medline

Dallman MF, Yates FE (1967) Anatomical and functional mapping of central neural input and feedback pathways of the adrenocortical system. Proc R Soc Med 60:904-905. Medline

Dautzenberg FM, Hauger RL (2002) The CRF peptide family and their receptors: yet more partners discovered. Trends Pharmacol Sci 23:71-77. CrossRef Medline

Dayanithi G, Forostyak O, Ueta Y, Verkhratsky A, Toescu EC (2012) Segregation of calcium signalling mechanisms in magnocellular neurones and terminals. Cell Calcium 51:293-299. CrossRef Medline

de Kock CP, Wierda KD, Bosman LW, Min R, Koksma JJ, Mansvelder HD, Verhage M, Brussaard AB (2003) Somatodendritic secretion in oxytocin neurons is upregulated during the female reproductive cycle. J Neurosci 23:2726-2734. Medline

Dergacheva O, Yamanaka A, Schwartz AR, Polotsky VY, Mendelowitz D (2017) Optogenetic identification of hypothalamic orexin neuron projections to paraventricular spinally projecting neurons. Am J Physiol Heart Circ Physiol 312:H808-H817. CrossRef Medline

Fenselau H, Campbell JN, Verstegen AM, Madara JC, Xu J, Shah BP, Resch JM, Yang Z, Mandelblat-Cerf Y, Livneh Y, Lowell BB (2017) A rapidly acting glutamatergic ARC $\rightarrow$ PVH satiety circuit postsynaptically regulated by $\alpha$-MSH. Nat Neurosci 20:42-51. CrossRef Medline

Ferguson AV, Latchford KJ, Samson WK (2008) The paraventricular nucleus of the hypothalamus - a potential target for integrative treatment of autonomic dysfunction. Expert Opin Ther Targets 12:717-727. CrossRef Medline

Füzesi T, Daviu N, Wamsteeker Cusulin JI, Bonin RP, Bains JS (2016) Hypothalamic CRH neurons orchestrate complex behaviours after stress. Nat Commun 7:11937. CrossRef Medline

Gainer H, Wolfe SA Jr, Obaid AL, Salzberg BM (1986) Action potentials and frequency-dependent secretion in the mouse neurohypophysis. Neuroendocrinology 43:557-563. CrossRef Medline

Gao Y, Zhou JJ, Zhu Y, Kosten T, Li DP (2017) Chronic unpredictable mild stress induces loss of GABA inhibition in corticotrophin-releasing hormone-expressing neurons through NKCC1 upregulation. Neuroendocrinology 104:194-208. CrossRef Medline

Gómez-Lira G, Lamas M, Romo-Parra H, Gutiérrez R (2005) Programmed and induced phenotype of the hippocampal granule cells. J Neurosci 25: 6939-6946. CrossRef Medline

Gosnell BA, Morley JE, Levine AS (1983) Adrenal modulation of the inhibitory effect of corticotropin releasing factor on feeding. Peptides 4:807812. CrossRef Medline

Haam J, Halmos KC, Di S, Tasker JG (2014) Nutritional state-dependent ghrelin activation of vasopressin neurons via retrograde trans-neuronal- 
glial stimulation of excitatory GABA circuits. J Neurosci 34:6201-6213. CrossRef Medline

Herman AM, Huang L, Murphey DK, Garcia I, Arenkiel BR (2014) Cell type-specific and time-dependent light exposure contribute to silencing in neurons expressing channelrhodopsin-2. Elife 3:e01481. CrossRef Medline

Herman JP, Figueiredo H, Mueller NK, Ulrich-Lai Y, Ostrander MM, Choi DC, Cullinan WE (2003) Central mechanisms of stress integration: hierarchical circuitry controlling hypothalamo-pituitary-adrenocortical responsiveness. Front Neuroendocrinol 24:151-180. CrossRef Medline

Hewitt SA, Wamsteeker JI, Kurz EU, Bains JS (2009) Altered chloride homeostasis removes synaptic inhibitory constraint of the stress axis. Nat Neurosci 12:438-443. CrossRef Medline

Hoffman NW, Tasker JG, Dudek FE (1991) Immunohistochemical differentiation of electrophysiologically defined neuronal populations in the region of the rat hypothalamic paraventricular nucleus. J Comp Neurol 307:405-416. CrossRef Medline

Iremonger KJ, Bains JS (2009) Retrograde opioid signaling regulates glutamatergic transmission in the hypothalamus. J Neurosci 29:7349-7358. CrossRef Medline

Justice NJ, Yuan ZF, Sawchenko PE, Vale W (2008) Type 1 corticotropinreleasing factor receptor expression reported in BAC transgenic mice: implications for reconciling ligand-receptor mismatch in the central corticotropin-releasing factor system. J Comp Neurol 511:479-496. CrossRef Medline

Lambert RC, Moos FC, Richard P (1993) Action of endogenous oxytocin within the paraventricular or supraoptic nuclei: a powerful link in the regulation of the bursting pattern of oxytocin neurons during the milkejection reflex in rats. Neuroscience 57:1027-1038. CrossRef Medline

Lazarenko RM, Milner TA, Depuy SD, Stornetta RL, West GH, Kievits JA, Bayliss DA, Guyenet PG (2009) Acid sensitivity and ultrastructure of the retrotrapezoid nucleus in Phox2b-EGFP transgenic mice. J Comp Neurol 517:69-86. CrossRef Medline

Leach GJ, Taylor MH (1980) The role of cortisol in stress-induced metabolic changes in fundulus heteroclitus. Gen Comp Endocrinol 42:219-227. CrossRef Medline

Lechan RM, Fekete C (2006) The TRH neuron: a hypothalamic integrator of energy metabolism. Prog Brain Res 153:209-235. CrossRef Medline

Lee S, Han TH, Sonner PM, Stern JE, Ryu PD, Lee SY (2008) Molecular characterization of T-type Ca2 channels responsible for low threshold spikes in hypothalamic paraventricular nucleus neurons. Neuroscience 155:1195-1203. CrossRef Medline

Li C, Chen P, Smith MS (1998) Neuropeptide Y (NPY) neurons in the arcuate nucleus $(\mathrm{ARH})$ and dorsomedial nucleus $(\mathrm{DMH})$, areas activated during lactation, project to the paraventricular nucleus of the hypothalamus (PVH). Regul Pept 75-76:93-100. Medline

Li DP, Chen SR, Pan HL (2002) Nitric oxide inhibits spinally projecting paraventricular neurons through potentiation of presynaptic GABA release. J Neurophysiol 88:2664-2674. CrossRef Medline

Liposits Z (1993) Ultrastructure of hypothalamic paraventricular neurons. Crit Rev Neurobiol 7:89-162. Medline

Liposits Z, Paull WK (1989) Association of dopaminergic fibers with corticotropin releasing hormone (CRH)-synthesizing neurons in the paraventricular nucleus of the rat hypothalamus. Histochemistry 93:119-127. CrossRef Medline

Liu P, Jenkins NA, Copeland NG (2003) A highly efficient recombineeringbased method for generating conditional knockout mutations. Genome Res 13:476-484. CrossRef Medline

Luther JA, Tasker JG (2000) Voltage-gated currents distinguish parvocellular from magnocellular neurones in the rat hypothalamic paraventricular nucleus. J Physiol 523:193-209. CrossRef Medline

Luther JA, Daftary SS, Boudaba C, Gould GC, Halmos KC, Tasker JG (2002) Neurosecretory and non-neurosecretory parvocellular neurones of the hypothalamic paraventricular nucleus express distinct electrophysiological properties. J Neuroendocrinol 14:929-932. CrossRef Medline

McEwen BS, Sapolsky RM (1995) Stress and cognitive function. Curr Opin Neurobiol 5:205-216. CrossRef Medline

Nahar J, Haam J, Chen C, Jiang Z, Glatzer NR, Muglia LJ, Dohanich GP, Herman JP, Tasker JG (2015) Rapid nongenomic glucocorticoid actions in male mouse hypothalamic neuroendocrine cells are dependent on the nuclear glucocorticoid receptor. Endocrinology 156:2831-2842. CrossRef Medline

Neumann I, Douglas AJ, Pittman QJ, Russell JA, Landgraf R (1996) Oxyto- cin released within the supraoptic nucleus of the rat brain by positive feedback action is involved in parturition-related events. J Neuroendocrinol 8:227-233. Medline

Oliet SH, Baimoukhametova DV, Piet R, Bains JS (2007) Retrograde regulation of GABA transmission by the tonic release of oxytocin and endocannabinoids governs postsynaptic firing. J Neurosci 27:1325-1333. CrossRef Medline

Paxinos G, Franklin KBJ (2008) The mouse brain in stereotaxic coordinates. San Diego, CA: Academic.

Perrin MH, Donaldson CJ, Chen R, Lewis KA, Vale WW (1993) Cloning and functional expression of a rat brain corticotropin releasing factor (CRF) receptor. Endocrinology 133:3058-3061. CrossRef Medline

Pervanidou P, Chrousos GP (2010) Neuroendocrinology of post-traumatic stress disorder. Prog Brain Res 182:149-160. CrossRef Medline

Petreanu L, Huber D, Sobczyk A, Svoboda K (2007) Channelrhodopsin-2assisted circuit mapping of long-range callosal projections. Nat Neurosci 10:663-668. CrossRef Medline

Pfeffer CK, Xue M, He M, Huang ZJ, Scanziani M (2013) Inhibition of inhibition in visual cortex: the logic of connections between molecularly distinct interneurons. Nat Neurosci 16:1068-1076. CrossRef Medline

Qiu DL, Chu CP, Shirasaka T, Tsukino H, Nakao H, Kato K, Kunitake T, Katoh T, Kannan H (2005) Corticotrophin-releasing factor augments the $\mathrm{I}(\mathrm{H})$ in rat hypothalamic paraventricular nucleus parvocellular neurons in vitro. J Neurophysiol 94:226-234. CrossRef Medline

Ramot A, Jiang Z, Tian JB, Nahum T, Kuperman Y, Justice N, Chen A (2017) Hypothalamic CRFR1 is essential for HPA axis regulation following chronic stress. Nat Neurosci 20:385-388. CrossRef Medline

Root DH, Mejias-Aponte CA, Zhang S, Wang HL, Hoffman AF, Lupica CR, Morales M (2014) Single rodent mesohabenular axons release glutamate and GABA. Nat Neurosci 17:1543-1551. CrossRef Medline

Saito M, Iwawaki T, Taya C, Yonekawa H, Noda M, Inui Y, Mekada E, Kimata Y, Tsuru A, Kohno K (2001) Diphtheria toxin receptor-mediated conditional and targeted cell ablation in transgenic mice. Nat Biotechnol 19:746-750. CrossRef Medline

Salata RA, Jarrett DB, Verbalis JG, Robinson AG (1988) Vasopressin stimulation of adrenocorticotropin hormone (ACTH) in humans. in vivo bioassay of corticotropin-releasing factor (CRF) which provides evidence for CRF mediation of the diurnal rhythm of ACTH. J Clin Invest 81:766774. CrossRef Medline

Shabel SJ, Proulx CD, Piriz J, Malinow R (2014) GABA/glutamate co-release controls habenula output and is modified by antidepressant treatment. Science 345:1494-1498. CrossRef Medline

Simmons DM, Swanson LW (2009) Comparison of the spatial distribution of seven types of neuroendocrine neurons in the rat paraventricular nucleus: toward a global 3D model. J Comp Neurol 516:423-441. CrossRef Medline

Son SJ, Filosa JA, Potapenko ES, Biancardi VC, Zheng H, Patel KP, Tobin VA, Ludwig M, Stern JE (2013) Dendritic peptide release mediates interpopulation crosstalk between neurosecretory and preautonomic networks. Neuron 78:1036-1049. CrossRef Medline

Spina M, Merlo-Pich E, Chan RK, Basso AM, Rivier J, Vale W, Koob GF (1996) Appetite-suppressing effects of urocortin, a CRF-related neuropeptide. Science 273:1561-1564. CrossRef Medline

Stern JE (2001) Electrophysiological and morphological properties of preautonomic neurones in the rat hypothalamic paraventricular nucleus. J Physiol 537:161-177. CrossRef Medline

Sutton RE, Koob GF, Le Moal M, Rivier J, Vale W (1982) Corticotropin releasing factor produces behavioural activation in rats. Nature 297:331333. CrossRef Medline

Swanson LW, Kuypers HG (1980) The paraventricular nucleus of the hypothalamus: cytoarchitectonic subdivisions and organization of projections to the pituitary, dorsal vagal complex, and spinal cord as demonstrated by retrograde fluorescence double-labeling methods. J Comp Neurol 194: 555-570. CrossRef Medline

Swanson LW, Sawchenko PE (1980) Paraventricular nucleus: a site for the integration of neuroendocrine and autonomic mechanisms. Neuroendocrinology 31:410-417. CrossRef Medline

Swanson LW, Sawchenko PE, Rivier J, Vale WW (1983) Organization of ovine corticotropin-releasing factor immunoreactive cells and fibers in the rat brain: an immunohistochemical study. Neuroendocrinology 36: 165-186. CrossRef Medline

Taniguchi H, He M, Wu P, Kim S, Paik R, Sugino K, Kvitsani D, Fu Y, Lu J, Lin 
Y, Miyoshi G, Shima Y, Fishell G, Nelson SB, Huang ZJ (2011) A resource of Cre driver lines for genetic targeting of GABAergic neurons in cerebral cortex. Neuron 71:995-1013. CrossRef Medline

Tasker JG, Dudek FE (1991) Electrophysiological properties of neurones in the region of the paraventricular nucleus in slices of rat hypothalamus. J Physiol 434:271-293. CrossRef Medline

Ugolini G (1995) Specificity of rabies virus as a transneuronal tracer of motor networks: transfer from hypoglossal motoneurons to connected second-order and higher order central nervous system cell groups. J Comp Neurol 356:457-480. CrossRef Medline

Ulrich-Lai YM, Herman JP (2009) Neural regulation of endocrine and autonomic stress responses. Nat Rev Neurosci 10:397-409. CrossRef Medline

Ulrich-Lai YM, Jones KR, Ziegler DR, Cullinan WE, Herman JP (2011) Forebrain origins of glutamatergic innervation to the rat paraventricular nucleus of the hypothalamus: differential inputs to the anterior versus posterior subregions. J Comp Neurol 519:1301-1319. CrossRef Medline

Vale W, Spiess J, Rivier C, Rivier J (1981) Characterization of a 41-residue ovine hypothalamic peptide that stimulates secretion of corticotropin and beta-endorphin. Science 213:1394-1397. CrossRef Medline

Wall NR, Wickersham IR, Cetin A, De La Parra M, Callaway EM (2010) Monosynaptic circuit tracing in vivo through Cre-dependent targeting and complementation of modified rabies virus. Proc Natl Acad Sci U S A 107:21848-21853. CrossRef Medline

Wamsteeker Cusulin JI, Füzesi T, Watts AG, Bains JS (2013a) Characterization of corticotropin-releasing hormone neurons in the paraventricular nucleus of the hypothalamus of Crh-IRES-Cre mutant mice. PLoS One 8:e64943. CrossRef Medline

Wamsteeker Cusulin JI, Füzesi T, Inoue W, Bains JS (2013b) Glucocorticoid feedback uncovers retrograde opioid signaling at hypothalamic synapses. Nat Neurosci 16:596-604. CrossRef Medline

Watabe-Uchida M, Zhu L, Ogawa SK, Vamanrao A, Uchida N (2012) Whole-brain mapping of direct inputs to midbrain dopamine neurons. Neuron 74:858-873. CrossRef Medline

Wickersham IR, Lyon DC, Barnard RJ, Mori T, Finke S, Conzelmann KK, Young JA, Callaway EM (2007) Monosynaptic restriction of transsynaptic tracing from single, genetically targeted neurons. Neuron 53:639647. CrossRef Medline

Wittmann G (2008) Regulation of hypophysiotrophic corticotrophinreleasing hormone- and thyrotrophin-releasing hormone-synthesising neurones by brainstem catecholaminergic neurones. J Neuroendocrinol 20:952-960. CrossRef Medline

Wu Z, Kim ER, Sun H, Xu Y, Mangieri LR, Li DP, Pan HL, Xu Y, Arenkiel BR, Tong Q (2015) GABAergic projections from lateral hypothalamus to paraventricular hypothalamic nucleus promote feeding. J Neurosci 35 : 3312-3318. CrossRef Medline

Yehuda R, Giller EL, Southwick SM, Lowy MT, Mason JW (1991) Hypothalamic-pituitary-adrenal dysfunction in posttraumatic stress disorder. Biol Psychiatry 30:1031-1048. CrossRef Medline

Yoo JH, Zell V, Gutierrez-Reed N, Wu J, Ressler R, Shenasa MA, Johnson AB, Fife KH, Faget L, Hnasko TS (2016) Ventral tegmental area glutamate neurons co-release GABA and promote positive reinforcement. Nat Commun 7:13697. CrossRef Medline

Ziegler DR, Edwards MR, Ulrich-Lai YM, Herman JP, Cullinan WE (2012) Brainstem origins of glutamatergic innervation of the rat hypothalamic paraventricular nucleus. J Comp Neurol 520:2369-2394. CrossRef Medline 